\title{
Stress Relief Cracking Susceptibility in High-Temperature Alloys
}

\section{Tests were developed to study the effect of postweld heat treatment temperature and cold working on stress relief cracking susceptibility}

\author{
BY R. KANT AND J. DUPONT
}

\begin{abstract}
The stress relief cracking (SRC) susceptibility of a range of austenitic and ferritic alloys was tested using Gleeble ${ }^{\circledR}$ based test procedures. The tests were developed to study the effect of postweld heat treatment (PWHT) temperature and cold working on the SRC susceptibility. Six susceptibility parameters were identified from the test results (ductility, percentage stress relaxed, hardness increase at fracture, failure time, fracture mode, and extent/type of secondary cracks below the fracture). The susceptibility parameters were integrated with concepts of Risk Priority Number (a prioritization tool in 6-Sigma) to develop an SRC susceptibility index. Sensitivity analysis of the methodology was done to ensure its robustness. The ferritic alloys generally showed the highest SRC susceptibility at a PWHT temperature of $600^{\circ} \mathrm{C}$, while the austenitic alloys were generally most susceptible at $800^{\circ} \mathrm{C}$. Using the susceptibility index, the SRC tendency of all the alloys was divided into three regions (highly susceptible, moderately susceptible, and resistant). The newly proposed test procedure and SRC susceptibility index provide a robust approach for studying and ranking the SRC susceptibility of engineering alloys. Posttest microstructural characterization of the SRC samples provided insight into the cracking mechanisms.
\end{abstract}

\section{KEYWORDS}

- Stress Relief Cracking • Stress Relaxation Cracking

- Residual Stress • Intergranular Cracking • Welding

- Precipitate Free Zone • Postweld Heat Treatment

\section{Introduction}

Fossil fuels continue to be an important source of power production. In 2015, coal, oil, and natural gas constituted more than $81 \%$ of the total fuel used for energy production in the world (Ref. 1). Although the dependence on fossil fuels for energy production is subject to the nation's economy, use of renewable sources for $100 \%$ energy production is still a distant goal. With the advent of advanced ultra-supercritical (A-USC) power plants, the efficiency of coal-fired power plants has increased to more than $45 \%$ from $35 \%$ efficiency of conventional power plants (Ref. 2). These A-USC power plants require alloys with good creep strength, capable of operating at elevated temperatures and pressures (steam conditions of $700^{\circ}-760^{\circ} \mathrm{C}$ and $4000-5000 \mathrm{lb} /$ in. $^{2}$ ) (Ref. 2). Due to the scale of these plants, the components must be made in parts and joined at the site of the application. Welding proves to be the best solution available for this purpose. One of the challenges associated with welding for some alloys is the problem of stress relief cracking (SRC). Stress relief cracking is known by different names, including stressrelaxation cracking, postweld heat treatment (PWHT) cracking, or stress-induced cracking. Strain-age cracking (SAC) has often been used alternatively for SRC by some researchers (Ref. 3). However, in this research, a distinction is made between SRC and SAC, where SRC is limited to cracking during PWHT while SAC failures occur during long-term service.

SRC is generally characterized by a low ductility intergranular (IG) fracture in the coarse-grain heat-affected zone (CGHAZ) and can further be aggravated in heavily cold worked regions like pipe bends (Refs. 4, 5). The fracture surface often exhibits localized microvoid coalescence on the grain facets that resembles creep fracture and suggests highly localized plastic deformation in the grain boundary regions. The problem of SRC has often been associated with precipitation-strengthened alloys. The mechanism of SRC is alloy specific but can generally be explained as the relaxation of residual stresses by plastic deformation that is localized along or near the grain boundaries. The localization of strain along the grain boundary regions can be associated with matrix strengthening and exacerbated by the formation of softened precipitate-free zones (PFZs) along the boundary (Ref. 6). When the local ductility is exhausted along the grain boundary region, the stress is relaxed by cracking (Refs. 3, 7). The soft PFZs that can aggravate cracking have generally been reported to be a result of two possible mechanisms - discontinuous coarsening of major strengthening precipitate near the grain boundary that 


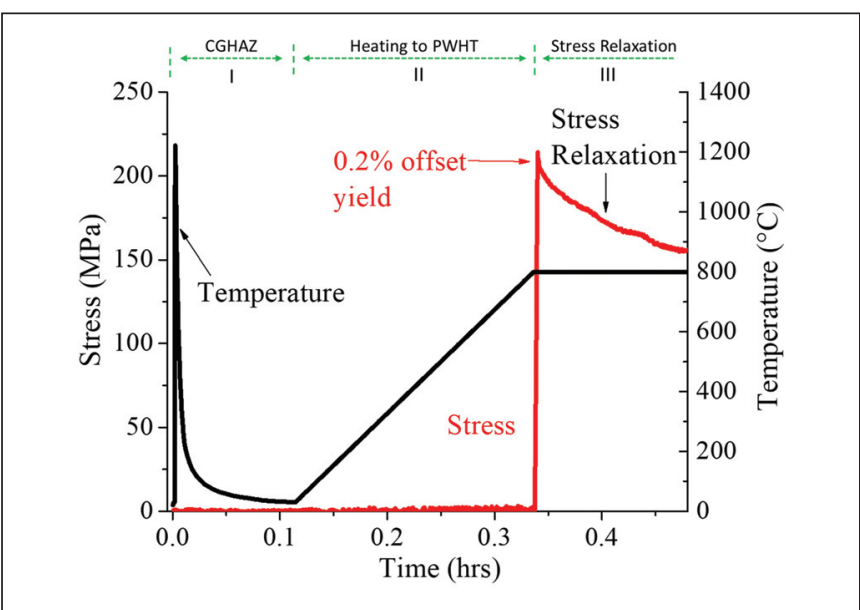

Fig. 1 - Schematic diagram of SRC test with $0.2 \%$ plastic strain.

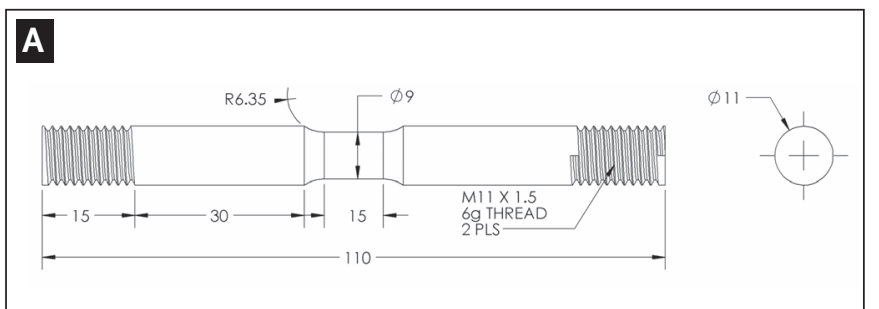

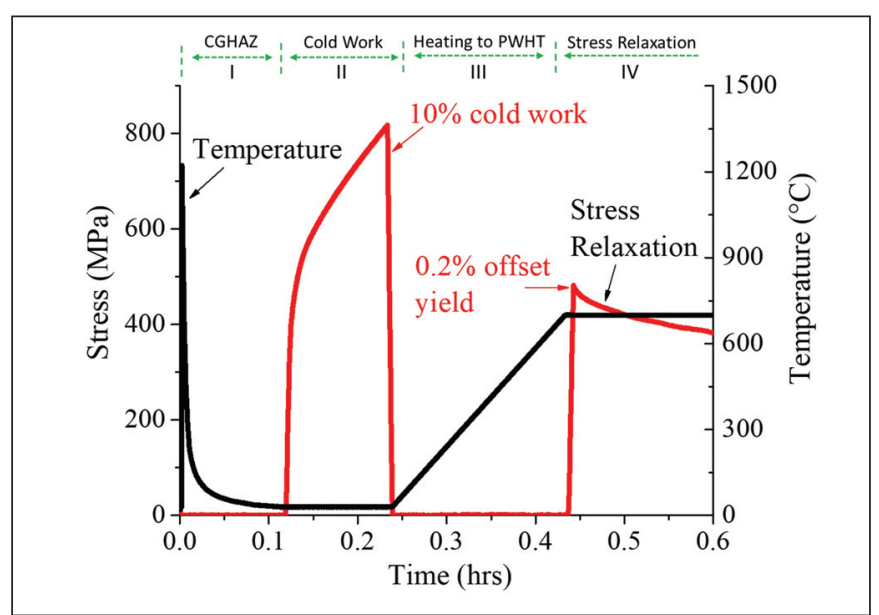

Fig. 2 - Schematic diagram of SRC test with $10 \%$ plastic strain.

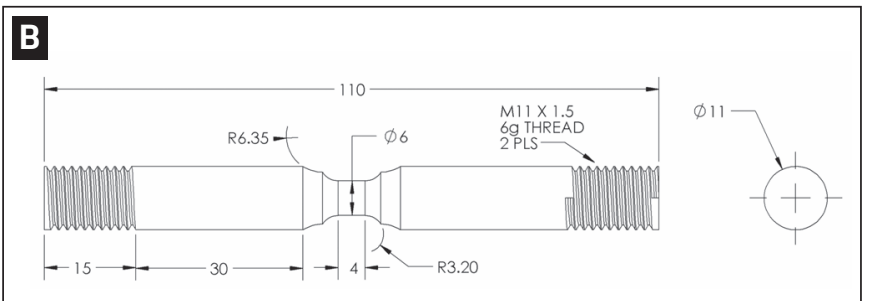

Fig. 3 - Sample geometry: A - austenitic; B - ferritic alloys. (All dimensions in $\mathrm{mm}$.)

leaves denuded zones between the coarsened particles, and local depletion of key alloying elements associated with precipitation/coarsening at the grain boundary (Ref. 8).

A relatively low precipitate content in the matrix allows for easy movement of dislocation (plastic deformation), which is an important mechanism of residual stress relaxation (Refs. 9-12). With increased precipitation at aging temperatures, the dislocations tend to pile up at the precip- tate-matrix interface, thus restricting stress relaxation (Ref. 11). The dislocation-precipitate interaction depends on a range of factors including the coherency of the precipitate with the matrix, size, and aging temperature (Refs. 11, 12). The impediment of dislocations is increased by cold working. Cold working generates new dislocations, which act as preferred sites for precipitate nucleation (Ref. 13). These new precipitates form within the grains or on subgrain

Table 1 - Chemical Composition of Alloys in Weight Percent

Chemical Composition

\begin{tabular}{|c|c|c|c|c|c|c|c|}
\hline & $740 \mathrm{H}$ & In 617 & HY282 & HY230 & $347 \mathrm{H}$ & Gr22 & Gr22V \\
\hline B & - & 0.0015 & 0.0038 & 0.0047 & $<0.0003$ & $<0.0003$ & 0.0014 \\
\hline Co & 20.21 & 12.37 & 10.12 & 0.127 & 0.156 & $<0.002$ & $<0.002$ \\
\hline $\mathrm{Cu}$ & 0.002 & 0.023 & 0.006 & 0.022 & 0.41 & 0.027 & 0.022 \\
\hline $\mathrm{Fe}$ & 0.11 & 0.8 & 0.49 & 2.5 & 69.92 & 95.78 & 95.51 \\
\hline $\mathrm{Mn}$ & 0.24 & 0.07 & 0.04 & 0.52 & 1.61 & 0.47 & 0.56 \\
\hline $\mathrm{Ni}$ & 50.53 & 53.94 & 58 & 58.04 & 9.06 & 0.03 & 0.03 \\
\hline$P$ & $<0.002$ & 0.002 & $<0.002$ & 0.004 & 0.03 & 0.004 & 0.005 \\
\hline $\mathrm{Si}$ & 0.149 & 0.05 & 0.039 & 0.38 & 0.44 & 0.187 & 0.057 \\
\hline $\mathrm{Ti}$ & 1.357 & 0.373 & 2.11 & 0.019 & 0.007 & 0.002 & 0.002 \\
\hline V & 0.006 & 0.012 & 0.004 & 0.024 & 0.058 & 0.004 & 0.304 \\
\hline w & 0.012 & 0.031 & 0.02 & 14.48 & 0.021 & $<0.002$ & $<0.002$ \\
\hline$C$ & 0.026 & 0.09 & 0.067 & 0.099 & 0.047 & 0.11 & 0.132 \\
\hline
\end{tabular}



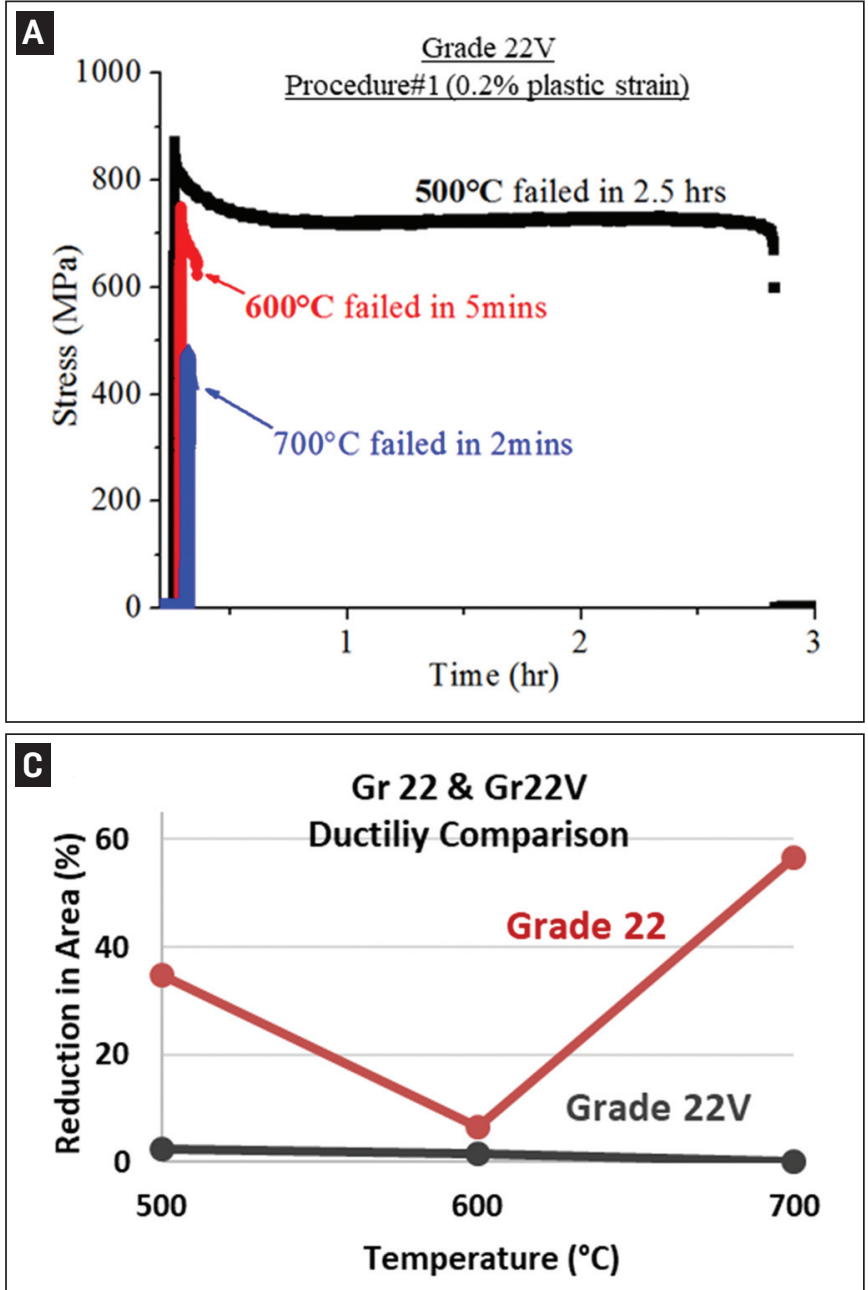

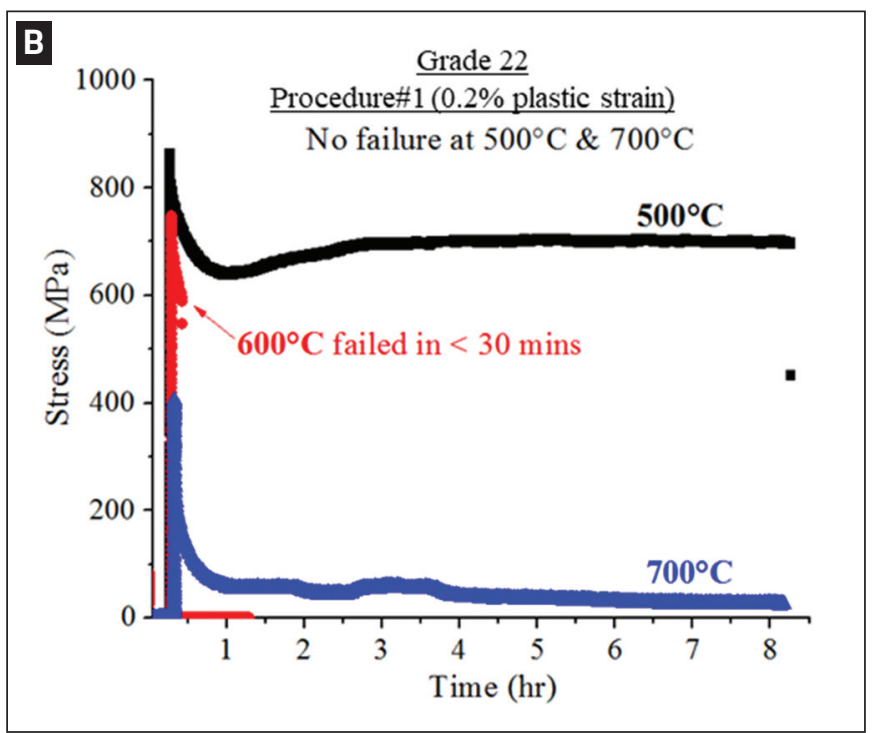

D

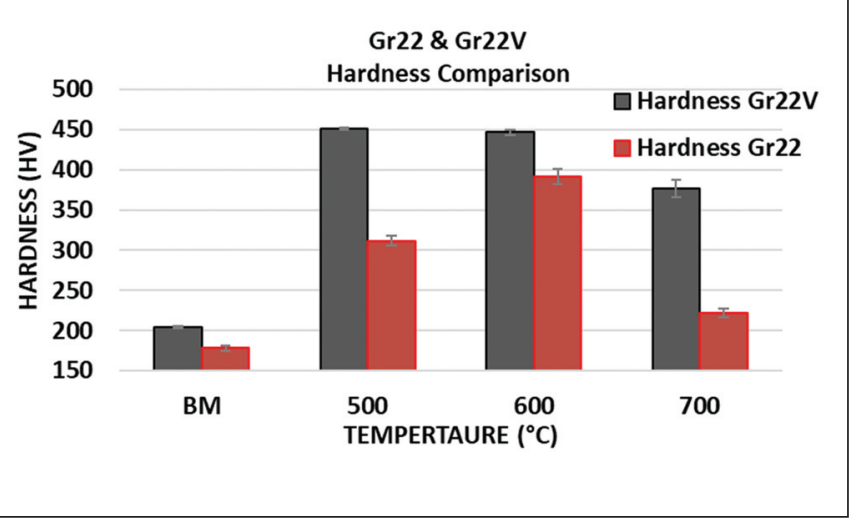

Fig. 4-A - Stress vs. time plot for Grade 22V; B - stress vs. time plot for Grade 22; C - ductility vs. PWHT temperature for Grades 22 and 22V; D - hardness at fracture vs. PWHT temperature for Grades 22 and 22V.

boundaries and impede the available mobile dislocations, thus accounting for reduced stress relaxation (Ref. 13).

The precipitation kinetics in an alloy is a crucial factor that affects its SRC susceptibility (Ref. 14). The stress relaxation during PWHT has been known to be a result of competition between elevated temperature plastic deformation to relax internal stresses and matrix strengthening due to aging at the same time (Ref. 15). Precipitation during aging hinders stress relaxation by impeding dislocations at the matrix-precipitate interface. Thus, fast precipitation kinetics can reduce the rate of stress relaxation, generally making

Table 2 - Peak Temperatures for CGHAZ Simulation in SMARTWELD

\begin{tabular}{cc} 
Material & Peak Temperature $\left({ }^{\circ} \mathrm{C}\right)$ \\
\hline Haynes 230 & 1247 \\
Haynes 282 & 1200 \\
347H & 1325 \\
Inconel 617 & 1225 \\
Inconel 740H & 1200 \\
Grade 22/22V & 1347 \\
\hline
\end{tabular}

the alloy more susceptible to SRC during PWHT (Ref. 7). It has been shown that effective stress relaxation without cracking can be achieved by fast heating to the PWHT temperature beyond the precipitate solvus temperature, thus avoiding any precipitation (Ref. 14).

Segregation of certain elements at the grain boundaries has also been indicated as one of the causes for SRC. Elevated temperature facilitates the diffusion of tramp elements like $S, P, A$ s to the grain boundaries. These elements cause embrittlement of grain boundaries and ultimately fracture (Ref. 16). The resultant fracture surface is characterized by smooth grain facets as compared to microvoids on the grain facets in the case of grain boundary softening. Both the fracture modes are IG and are characteristic to SRC.

Many past studies on the SRC susceptibility were more binary in their approach where the test methods were designed to indicate pass or fail for an alloy or a combination of two alloys (Refs. 4, 9, 17-19). The primary objectives of this research were to 1 ) develop a reliable test procedure that simulates the SRC mechanism under controlled conditions and provides a relative, quantitative measure of SRC susceptibility, and 2) apply the test method to rank a wide range of alloys to determine the relative SRC susceptibility 


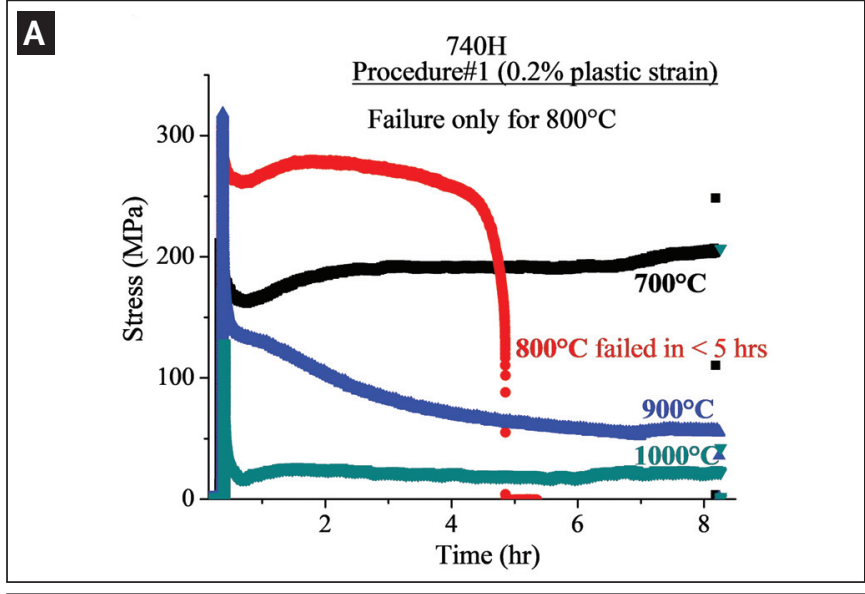

C

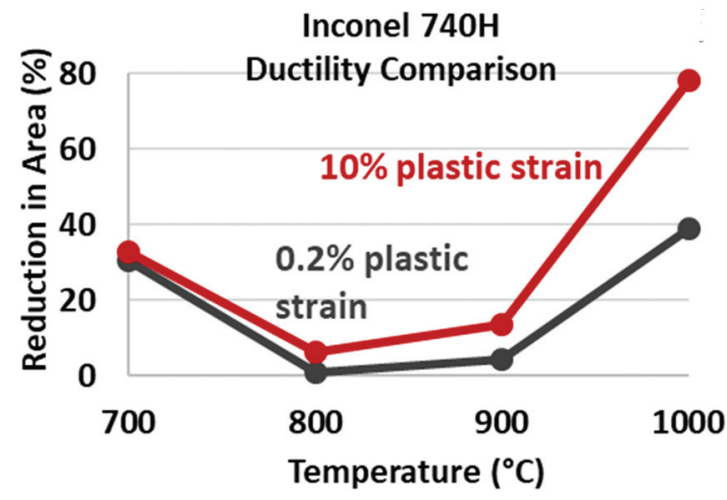

B

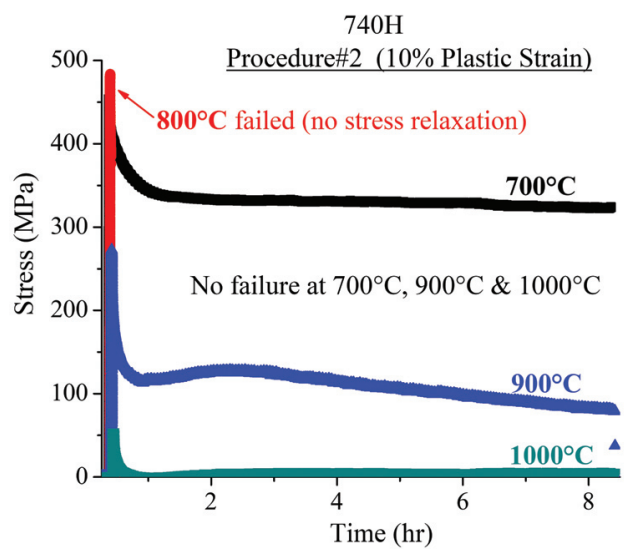

D

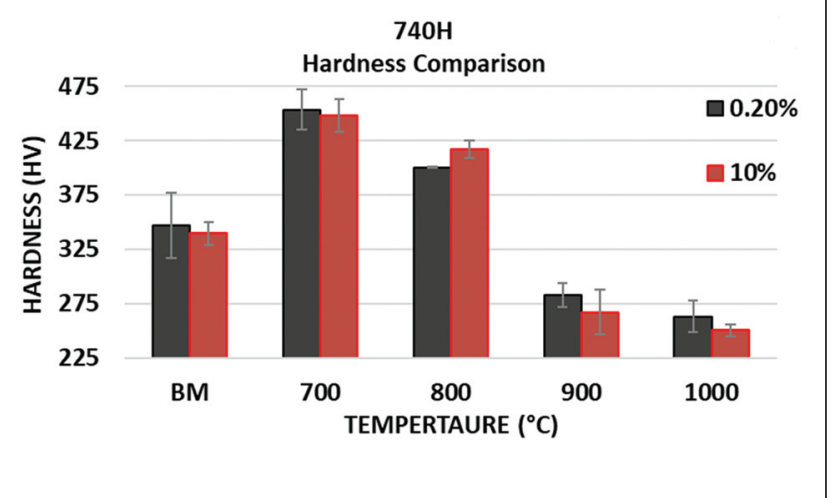

Fig. $5-A-$ Stress vs. time plot for $740 \mathrm{H}$ with procedure 1 ( $0.2 \%$ plastic strain); B - stress vs. time plot for $740 \mathrm{H}$ with procedure 2 (10\% plastic strain); $C$ - ductility vs. temperature for both procedures 1 and 2 for $740 \mathrm{H} ; D$ - hardness at fracture vs. temperature for both procedures 1 and 2 for $740 \mathrm{H}$.

as a function of PWHT temperature and plastic deformation. Post-test microstructural characterization of the samples was also conducted to gain insight into the cracking mechanisms of alloys that were susceptible.

\section{Procedure}

The chemical composition of the alloy systems under consideration is listed in Table 1. Of the seven alloys, Grade 22 and Grade $22 \mathrm{~V}$ are ferritic steels, $347 \mathrm{H}$ is an austenitic stainless steel, Inconel ${ }^{\circledR} 740 \mathrm{H}$, Inconel ${ }^{\circledR} 617$, Haynes ${ }^{\circledR} 230$, and Haynes ${ }^{\circledR} 282$ are Ni-based alloys. A Gleeble ${ }^{\circledR} 3500$ thermo-mechanical simulator was used in this study to develop SRC tests that reproduced the fracture features typical of SRC failures.

Figure 1 shows a schematic illustration of the thermal and mechanical cycle during a basic SRC test. The SRC test was divided into three stages. First, the specimen was exposed to a CGHAZ thermal cycle. The CGHAZ thermal cycle for each material was obtained using the Smartweld ${ }^{\circledR}$ package with a representative heat input of $2000 \mathrm{~J} / \mathrm{mm}$. Table 2 lists the peak temperatures of the CGHAZ thermal cycles for all the alloys. After the CGHAZ thermal cycle, the sample was cooled to room temperature, followed by heating to the

Table 3 - Base Metal and HAZ Grain Size Along with Standard Deviation

Grain Size \pm Std. Deviation $(\mu \mathrm{m})$

\begin{tabular}{ccr}
\hline Material & Base Metal & Heat-Affected \\
Haynes 230 & $47 \pm 4$ & $61 \pm 6$ \\
Haynes 282 & $92 \pm 11$ & $133 \pm 13$ \\
347H & $18 \pm 1$ & $32 \pm 1$ \\
Inconel 617 & $89 \pm 10$ & $86 \pm 5$ \\
Inconel 740H & $116 \pm 11$ & $169 \pm 12$ \\
Grade 22 & $17 \pm 1$ & $94 \pm 8$ \\
Grade 22V & $21 \pm 3$ & $70 \pm 5$
\end{tabular}




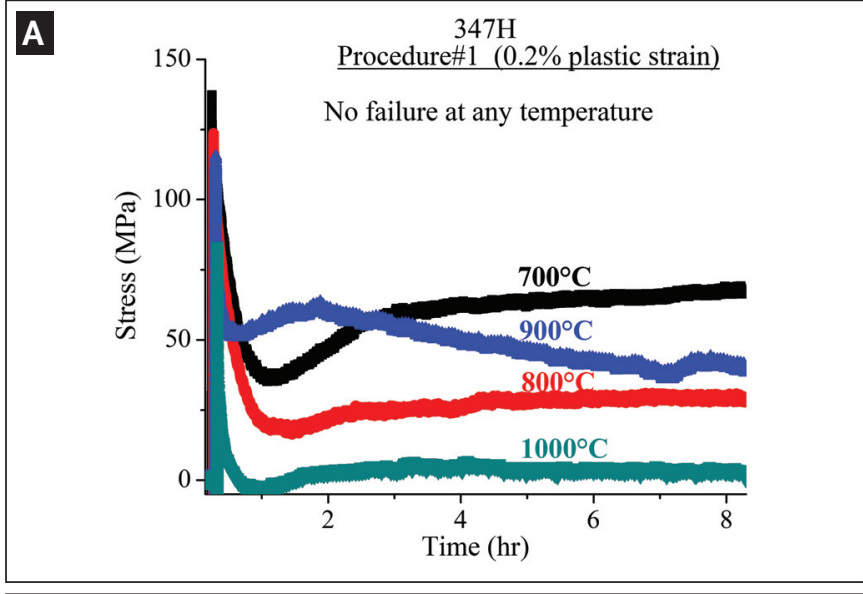

C

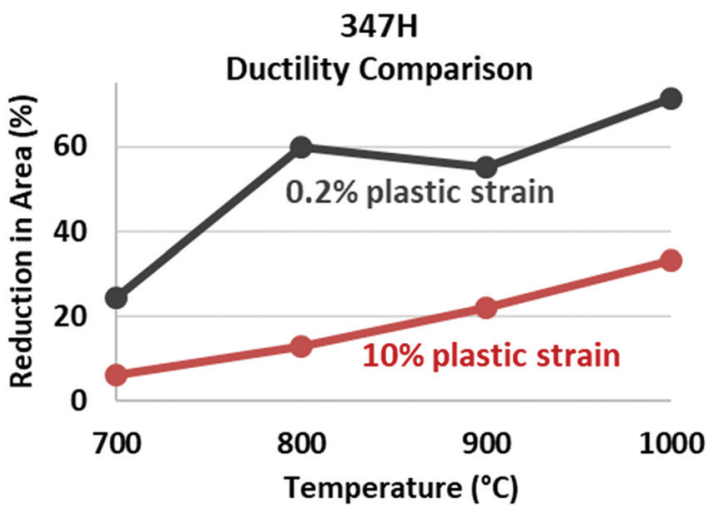

B

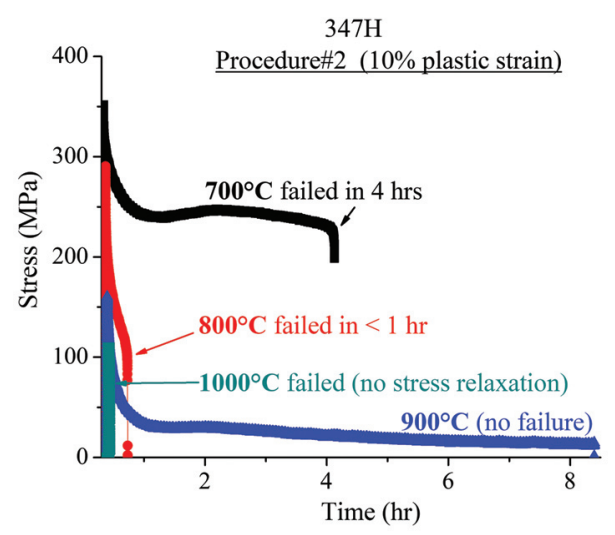

D

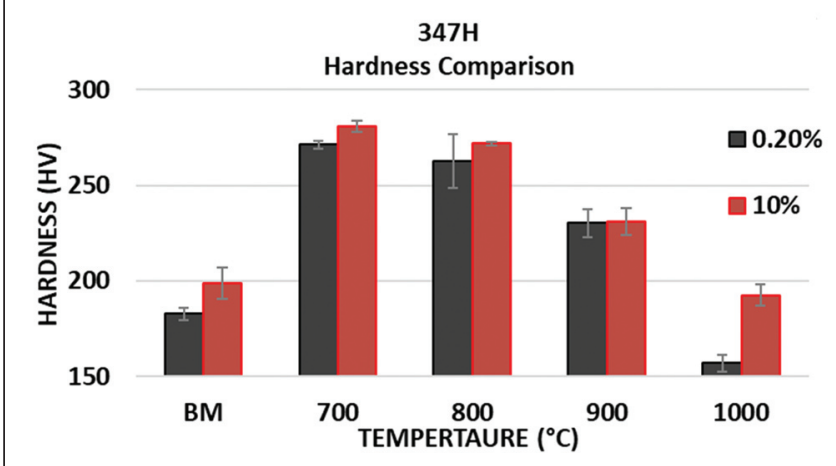

Fig. $6-A-$ Stress vs. time plot for $347 \mathrm{H}$ with procedure 1 ( $0.2 \%$ plastic strain); B - stress vs. time plot for $347 \mathrm{H}$ with procedure 2 (10\% plastic strain); $C$ - ductility vs. temperature for both procedures 1 and 2 for $347 \mathrm{H}$; $D$ - hardness at fracture vs. temperature for both procedures 1 and 2 for $347 \mathrm{H}$.

PWHT temperature at $100^{\circ} \mathrm{C} / \mathrm{min}$. During the first two stages of the SRC test, the sample was not constricted and thus could freely expand/contract due to volumetric changes associated with heating/cooling. Once at the PWHT temperature, the $0.2 \%$ offset yield stress (at test temperature) was applied at $1.5 \mathrm{~mm} / \mathrm{min}$ crosshead speed and the crosshead was locked at this position. The crosshead was held fixed for $8 \mathrm{~h}$ during which the variation of stress with time was recorded at a constant temperature, shown by the third stage of the SRC test in Fig. 1. Locking the crosshead mimicked the constriction experienced by the HAZ of a weld during stress relaxation at the PWHT temperature. The test stopped before $8 \mathrm{~h}$ if the sample fractured during stress relaxation, otherwise the sample was pulled to failure at 2.5 $\mathrm{mm} / \mathrm{s}$ at the end of $8 \mathrm{~h}$ of stress relaxation.

The high strain rate was employed to quickly separate the fracture surfaces to help prevent arcing between the mating faces of the crack, thus preserving the fracture surface for post-test examination. As described above, the SRC procedures required knowledge of the $0.2 \%$ offset yield strength for each PWHT temperature of interest. Thus, prior to the SRC tests, tensile tests were conducted at each PWHT temperature for each alloy. The strain during the tensile tests was measured using a dilatometer, measuring the change in diameter at the center of the sample. The tensile test sam- ples were exposed to the same CGHAZ thermal cycle as the SRC test for that alloy.

The procedure was modified to study the effect of cold work on the SRC behavior because cold working is well known to accelerate precipitation kinetics and increase SRC susceptibility (Refs. 9, 10-13). Ten percent plastic strain was applied to the sample at room temperature after application of the CGHAZ thermal cycle, as shown in stage two of Fig. 2.

Stage two terminated with bringing the stress on sample to zero. The sample was then heated to the PWHT temperature while maintaining zero stress on the sample (i.e., unconstrained). At the PWHT temperature, the $0.2 \%$ offset yield stress was applied to the sample and the crosshead was locked in place to start the stress relaxation (for $8 \mathrm{~h}$ ). The $0.2 \%$ offset yield strength for these tests were remeasured at each PWHT temperature after application of $10 \%$ plastic strain (the earlier measured values could not be used as the application of $10 \%$ plastic strain increased the yield strength of the alloys). The ferritic alloys were only investigated with $0.2 \%$ plastic strain at temperatures of $500^{\circ}, 600^{\circ}$, and $700^{\circ} \mathrm{C}$. The austenitic alloys were tested with both $0.2 \%$ and $10 \%$ plastic strains at temperatures of $700^{\circ}$ through $1000^{\circ} \mathrm{C}$ in increments of $100^{\circ} \mathrm{C}$.

Figure $3 \mathrm{~A}$ and $\mathrm{B}$ show the sample geometry used for the austenitic and ferritic alloys, respectively. For the ferritic al- 


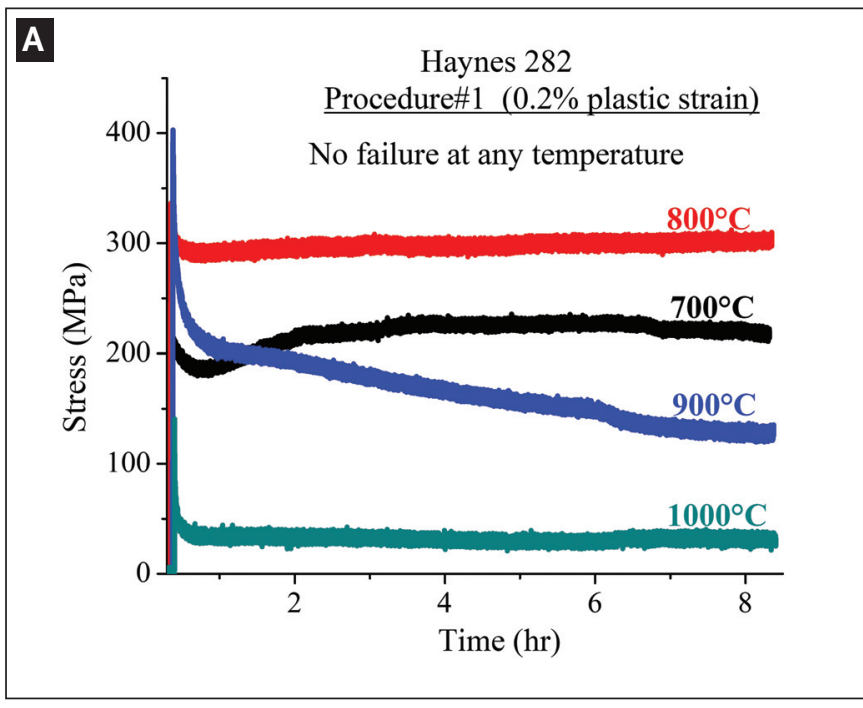

C

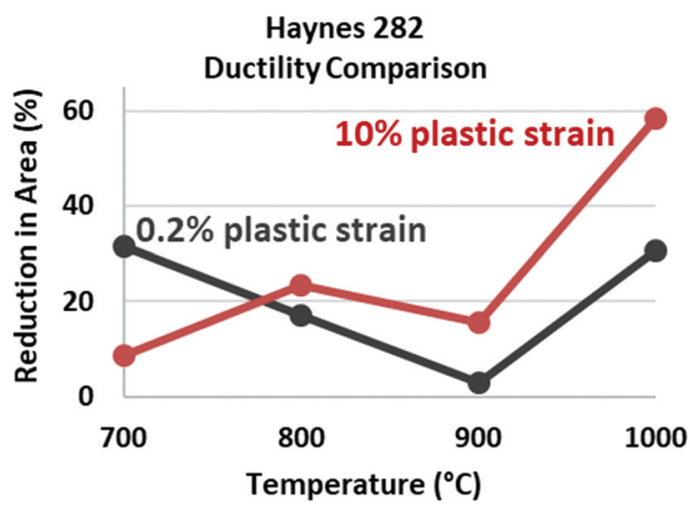

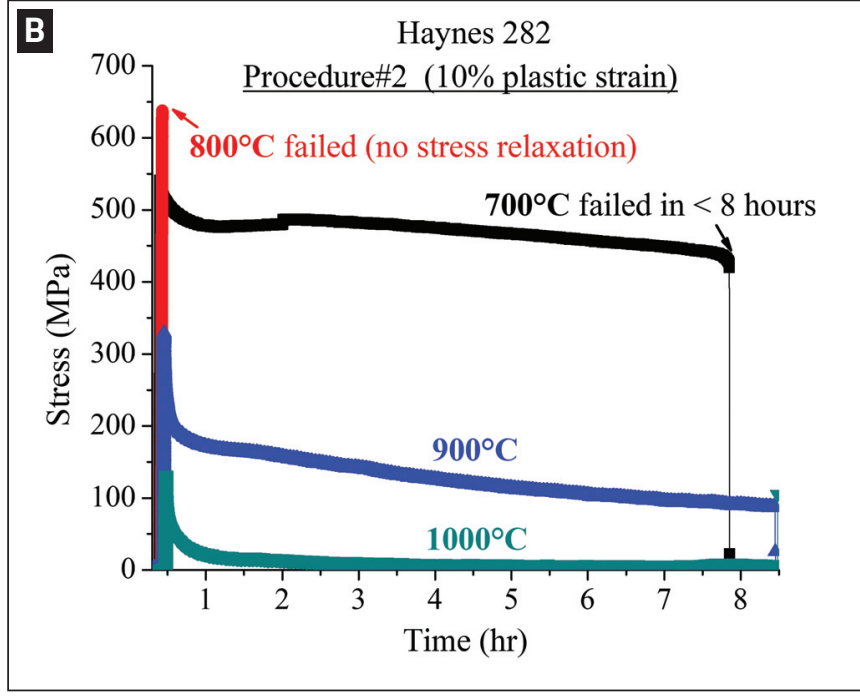

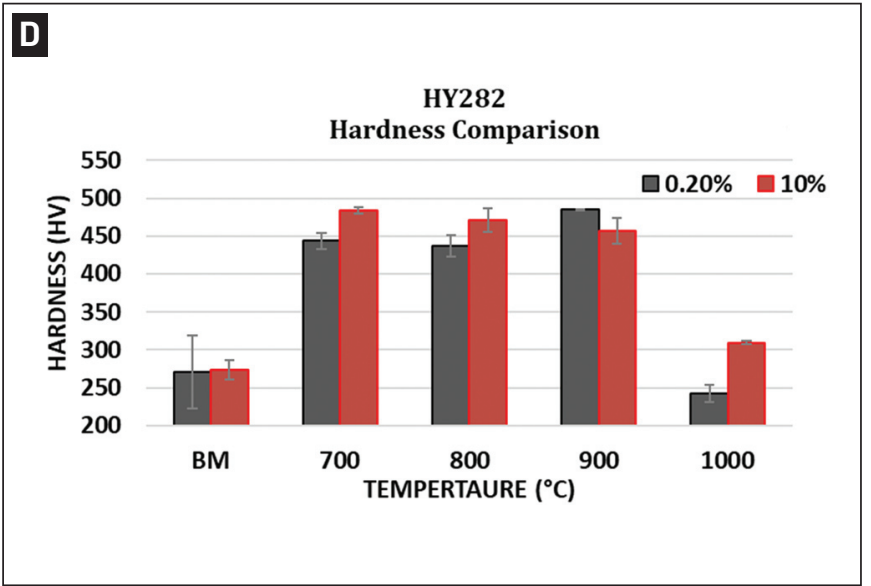

Fig. $7-A-$ Stress vs. time plot for Haynes ${ }^{\circledR} 282$ with procedure 1 (0.2\% plastic strain); B - stress vs. time plot for Haynes ${ }^{\circledR} 282$ with procedure 2 (10\% plastic strain); C - ductility vs. temperature for both procedures 1 and 2 for Haynes ${ }^{\circledR} 282$; $D-$ hardness at fracture vs. temperature for both procedures 1 and 2 for Haynes ${ }^{\circledR} 282$.

loys, a double-reduced geometry was devised to prevent failure occurring away from the center of the sample. Failure away from the center of the sample was associated with martensite formation during the CGHAZ thermal cycle. Martensite is stronger than the unaffected base metal outside the hot zone that is primarily bainite. Thus, with a sample of the uniform cross section, the weaker section will fail before the CGHAZ. The double-reduced area within the hot zone increases the stress at the smallest cross section, thus ensuring fracture occurs within the simulated CGHAZ in the sample where the microstructure and temperature are controlled.

After the SRC tests, one half of the sample was used for fracture surface analysis on a Hitachi $4300^{\circledR}$ or Zeiss LEO $1550 \mathrm{VP}^{\circledR}$ scanning electron microscope (SEM). The other half of the sample was sectioned longitudinally, mounted, and metallographically prepared for microstructural characterization. Microhardness traces were conducted on a Leco ${ }^{\circledR}$ microhardness tester from near the fracture surface to the unaffected base metal. The samples were then repolished down to $0.05-\mu \mathrm{m}$ colloidal silica and etched. A $2 \%$ Nital solution was used to etch the ferritic steels while a $10 \%$ Oxalic solution was used to electrolytically etch $347 \mathrm{H}$, Inconel 617 , and Haynes 230 at 4 V DC. The $740 \mathrm{H}$ and Haynes 282 samples were electrolytically etched at $6 \mathrm{~V} \mathrm{DC}$ in an $88-12 \%$ solution of $\mathrm{H}_{3} \mathrm{PO}_{4}$ and $\mathrm{H}_{2} \mathrm{SO}_{4}$ saturated with $\mathrm{CrO}_{3}$. The microstructure in the etched samples was first viewed under a Reichert-Jung $\mathrm{MeF}^{\circledR}{ }^{\circledR}$ light optical microscope (LOM) or Olympus BH $2^{\circledR}$ fitted with Pax-It ${ }^{\circledR}$ LOM. Grain size measurements were done on the Pax-It ${ }^{\circledR}$ software using the Abrams three circle method averaged over five fields of views as per ASTM E112 (Ref. 20). Table 3 summarizes the base metal and HAZ grain size measurements.

\section{Results and Discussion}

Figure 4 shows typical results acquired during the SRC tests, using alloys Grade 22 and Grade 22V as examples. Figure $4 \mathrm{~A}$ and $\mathrm{B}$ show the stress relaxation plots with the failure times indicated (when failure ocurred). Two measures of SRC susceptibility, time to failure and percentage stress relaxed during the test, can be determined from the stress relaxation plots. For both the measures, a lower value indicates higher susceptibility to SRC. Figure $4 C$ shows the reduction in area associated with each test condition, where a lower ductility value generally indicates reduced plastic de- 


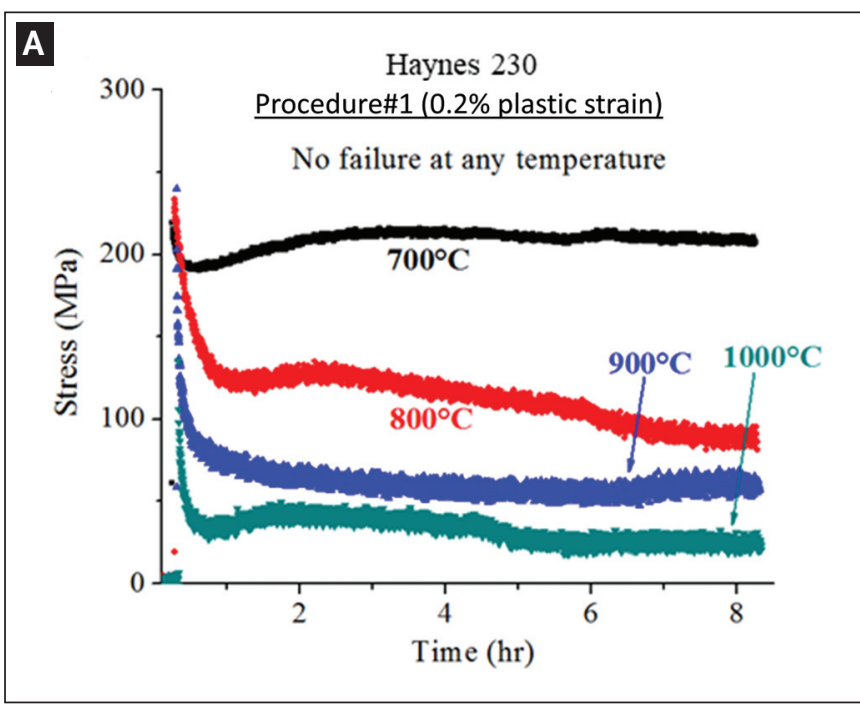

C

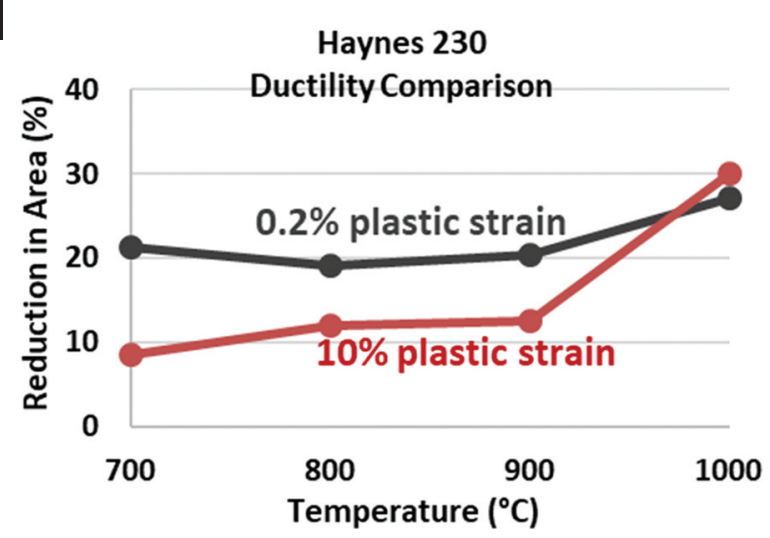

B

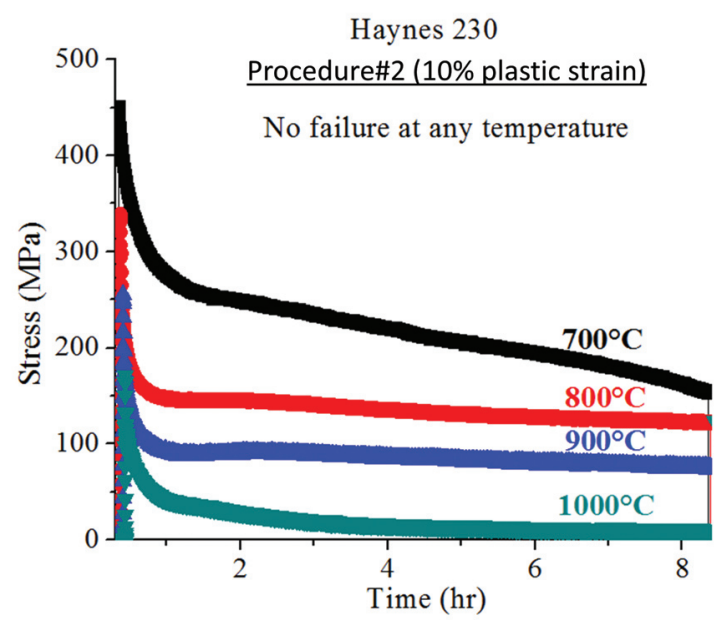

D

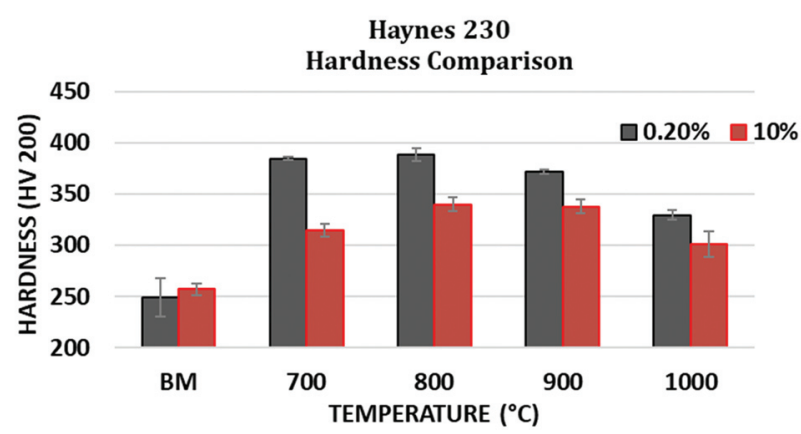

Fig. $8-A-$ Stress vs. time plot for Haynes ${ }^{\circledR} 230$ with procedure $1\left(0.2 \%\right.$ plastic strain); B - stress vs. time plot for Haynes ${ }^{\circledR} 230$ with procedure 2 (10\% plastic strain); C - ductility vs. temperature for both procedures 1 and 2 for Haynes ${ }^{\circledR} 230 ; D$ - hardness at fracture vs. temperature for both procedures 1 and 2 for Haynes ${ }^{\circledR} 230$.

formation available for stress relaxation. Thus, lower ductility indicates higher SRC susceptibility. Figure 4D shows the change in hardness near the fracture relative to the base metal. Hardening near the fracture can be indicative of matrix strengthening due to precipitation, which can exacerbate SRC susceptibility. For samples that did not fail during the test, it is recognized that this local hardness increase could also be associated with work hardening when the sample was pulled to failure at the end of the test. Hence, hardness values cannot solely indicate SRC susceptibility but can surely complement other susceptibility measures. Similar results are shown for the austenitic alloys in Figs. 5-9 for the SRC tests conducted with both 0.2 and $10 \%$ plastic strain.

The fracture mode for each condition was determined by examination of the fracture surfaces with SEM, and four distinct types of fracture modes were observed. Examples of each fracture mode are shown in Fig. 10 with their respective reduction in area values. The Type I and II fracture modes shown in Fig. 10A and B, respectively, are IG with very low ductility. Both Type I and II demonstrate susceptibility to SRC as the alloys failed during the test.

The grain facets in Type I are smooth, indicating a brittle grain boundary region with no evidence of significant local- ized plastic deformation. In contrast, the Type II fractures exhibit grain facets with microvoid coalescence (MVC), suggesting localized softening near the grain boundary. The type III fracture mode shown in Fig. 10C is a mixed type of IG and ductile MVC with moderate ductility. Thus, Type III fracture mode indicates moderate susceptibility to SRC. The Type IV fracture mode shown in Fig. 10D is completely ductile with MVC. High ductility at the end of SRC test indicates that the alloy can accommodate plastic strain and hence is resistant to SRC. The Type III and IV fracture surfaces are from the samples that did not fail during the test and hence were pulled to failure at the end of $8 \mathrm{~h}$.

Similarly, four major types of secondary cracks were observed below the fracture surface as shown in Fig. 11. The Type I secondary cracks shown in Fig. 11A exhibit extensive IG cracking with equiaxed grains and low ductility. Minimal plastic deformation of the grains (as evident by the preserved equiaxed grain structure) with IG secondary cracks is indicative of cracking being the active mechanism of stress relaxation. Hence, Type I secondary cracks demonstrate high SRC susceptibility. The Type II cracks (Fig. 11B) are also rather sharp and intergranular, but with lower frequency than Type I cracks. In addition, samples with Type II cracks 
Table 4- Assigned Values of 'Severity' and 'Detectability' for All Susceptibility Parameters. (Below each value is the range used in sensitivity analysis.)

$\begin{array}{cccccc}\text { Ductility } & \text { \% Stress Relaxed } & \text { Hardness at Fracture } & \text { Failure Time } & \text { Fracture Mode } & \text { Intergranular Secondary } \\ \text { (P1) } & \text { (P2) } & \text { (P3) } & \text { (P4) } & \text { (P5) } & \text { (P6) }\end{array}$

\begin{tabular}{ccccccc}
\hline $\begin{array}{c}\text { Severity } \\
(\mathrm{x} / 10)\end{array}$ & 8 & 8 & 6 & 10 & 10 & 10 \\
$\begin{array}{c}\text { Effect } \\
\text { on output }\end{array}$ & $6 \leftrightarrow 10$ & $6 \leftrightarrow 10$ & $4 \leftrightarrow 10$ & $6 \leftrightarrow 10$ & $6 \leftrightarrow 10$ & $6 \leftrightarrow 10$ \\
\hline $\begin{array}{c}\text { Detectability } \\
(x / 10)\end{array}$ & 10 & 10 & 10 & 10 & 8 & 8 \\
$\begin{array}{c}\text { Ease of } \\
\text { detection }\end{array}$ & $6 \leftrightarrow 10$ & $6 \leftrightarrow 10$ & $6 \leftrightarrow 10$ & $6 \leftrightarrow 10$ & $6 \leftrightarrow 10$ & $6 \leftrightarrow 10$ \\
\hline
\end{tabular}

exhibit slightly increased plasticity (as indicated by the elongated grains) that is indicative of lower SRC susceptibility as compared to Type I. The Type III cracks (Fig. 11C) are intergranular, but the cracks are rounded with evidence of blunting associated with appreciable plastic deformation. Finally, samples with Type IV cracks (Fig. 11D) exhibit extensive plasticity (MVC) and no failure during the SRC test, thus show resistance to SRC under the test conditions.

As discussed above, six measures of SRC susceptibility can be identified from the SRC test results: time to failure, percentage stress relaxed, ductility, increase in hardness at the fracture (compared to base metal), type of fracture mode, and nature of secondary cracks below the fracture. These measures are referred to as susceptibility parameters (SP) in this work. Higher susceptibility to SRC is correlated to reductions in the failure time, amount of stress relaxed, and ductility. An increase in hardness at the fracture relative the base metal would also indicate increased SRC susceptibility, as would Types I and II fracture surfaces and secondary cracks. It may not be conclusive to comment on SRC susceptibility based on only a single parameter. However, when integrated together, these parameters correlate very well with SRC susceptibility among all the alloys. For example, as shown in Fig. 4A, C, and D, Grade 22V at all test temperatures $\left(500^{\circ}, 600^{\circ}, 700^{\circ} \mathrm{C}\right)$ failed during the tests with short failure times ( $2.5 \mathrm{~h}, 5 \mathrm{~min}, 2 \mathrm{~min}$, respectively) and with limited stress relaxation. Very low ductility $(\sim 2 \%)$ and high hardness near the fracture were also observed. Higher hardness near the fracture, in this case, can be attributed to transformation to martensite from the originally bainitic structure due to HAZ thermal cycle and also precipitation strengthening at PWHT temperatures (Refs. 21, 22). Fine, dispersed vanadium carbides are reported to form on dislocations in Grade $22 \mathrm{~V}$ that provide enhanced strengthening (Refs. 21, 22). Also, as the sample failed with minimal ductility, the contribution of work hardening to hardness increase is negligible. As shown in Fig. 10A and B, the fracture surfaces were all IG Type I and II with IG Type I secondary cracks. Therefore, combining all the parameters, it can be conclusively stated that Grade $22 \mathrm{~V}$ is highly susceptible to SRC under the $0.2 \%$ test conditions. Several other alloys and test conditions showed similar results (e.g., Inconel $740 \mathrm{H}$ at $800^{\circ} \mathrm{C}$ with both $0.2 \%$ and $10 \%$ plastic strain, both $347 \mathrm{H}$ and Haynes 282 at $700^{\circ}$ and $800^{\circ} \mathrm{C}$ with $10 \%$ plastic strain, and Grade 22 at $600^{\circ} \mathrm{C}$ with $0.2 \%$ plastic strain). Some alloys did not fail during the test but showed other characteristics of SRC susceptibility. These alloys and test conditions had low ductility when pulled to failure and exhibited Type I to Type III fracture modes and secondary cracks (e.g., Haynes 230 at $700^{\circ}$ and $800^{\circ} \mathrm{C}$ with $10 \%$ plastic strain, Inconel $740 \mathrm{H}$ at $900^{\circ} \mathrm{C}$ with both 0.2 and $10 \%$ plastic strain). Finally, there were alloys that showed no signs of SRC susceptibility as indicated by no fracture during the test, very high ductility when pulled to failure (after $8 \mathrm{~h}$ of the test), Type IV both fracture mode and secondary cracks, and a high stress relaxation. Examples in this category include Inconel 617, Haynes 282, and Inconel $740 \mathrm{H}$ at $1000^{\circ} \mathrm{C}$ with both 0.2 and $10 \%$ plastic strain.

The results also revealed the important effects of PWHT temperature on the SRC susceptibility. Broadly, it can be stated that the ferritic alloys were most susceptible at $600^{\circ} \mathrm{C}$ followed by $700^{\circ} \mathrm{C}$, while austenitic alloys were observed to be the most susceptible at both $700^{\circ}$ and $800^{\circ} \mathrm{C}$ followed by $900^{\circ} \mathrm{C}$. Irrespective of the alloy, SRC susceptibility was found to be minimal at $1000^{\circ} \mathrm{C}$.

Other than temperature, SRC susceptibility also showed a strong dependence on plastic strain. Some alloys were not susceptible with $0.2 \%$ plastic strain but showed evidence of susceptibility when $10 \%$ plastic strain was applied. For example, $347 \mathrm{H}$ at $700^{\circ}$ and $800^{\circ} \mathrm{C}$ with $0.2 \%$ plastic strain did not fail during the test, had high ductility when pulled to failure with Type IV fracture mode, and secondary cracks. However, upon application of $10 \%$ plastic strain, failure occurred during the test with low-stress relaxation, increased hardness at the fracture, Type I fracture mode and secondary cracks. This change in SRC susceptibility in $347 \mathrm{H}$ sample can probably be attributed to the $\mathrm{NbC}$ precipitation on the dislocations induced by cold working (Ref. 23). Cold working enhances the dislocation density in the matrix, thus generating more precipitation sites for $\mathrm{NbC}$. This matrix strengthening can therefore localize strain at the grain boundaries leading to IG fracture with low ductility. Comparable results were observed for Haynes 282 and 230 at $700^{\circ}$ and $800^{\circ} \mathrm{C}$ with $10 \%$ plastic strain. However, it should be noted that the mechanism of matrix strengthening is alloy specific. For example, Haynes 282 is $\gamma^{\prime}$ precipitation strengthened while solid solution strengthening is the active hardening mechanism in Haynes 230. (The microstructural mechanisms of SRC are discussed in more detail below.)

From the above discussion, the SRC susceptibility can be ascertained as a combination of the SP values identified in 

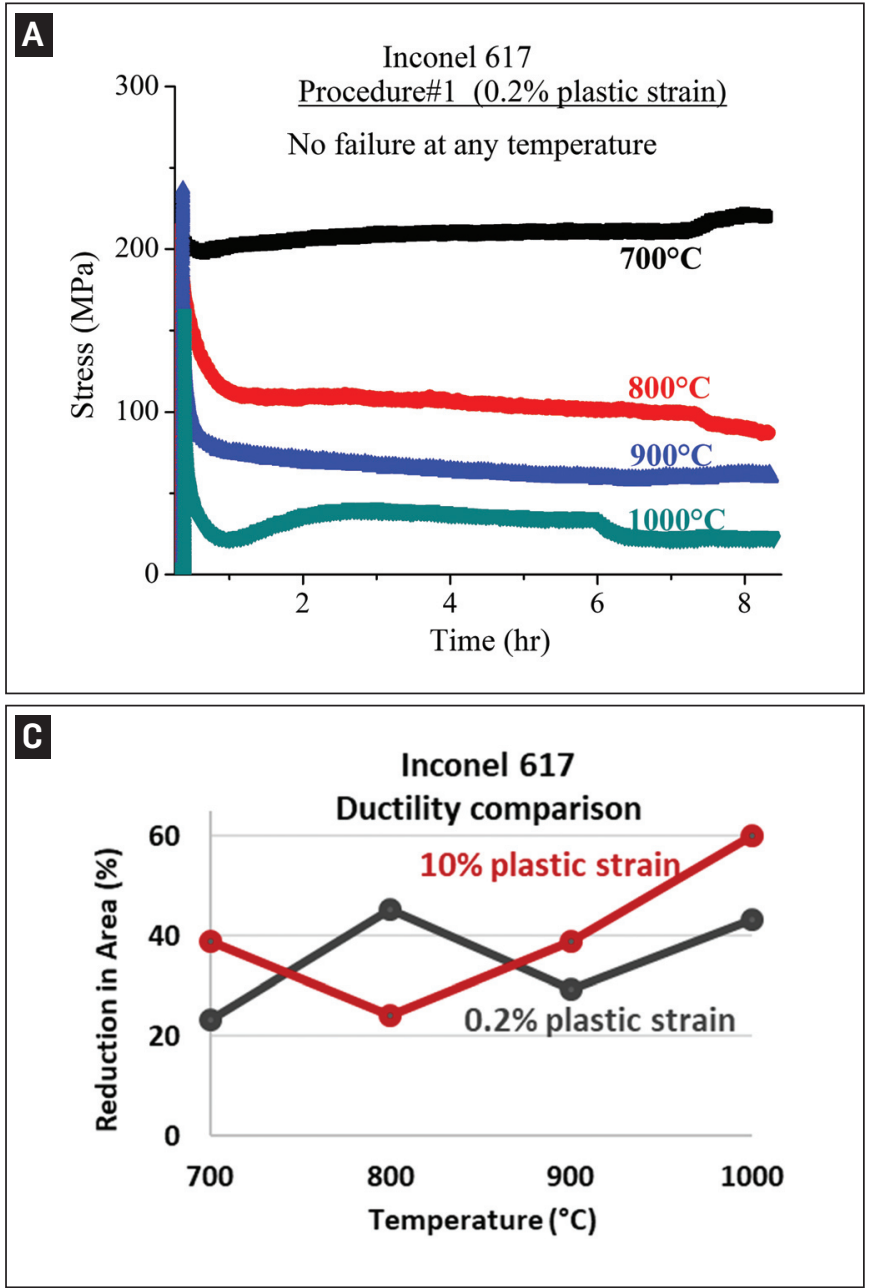

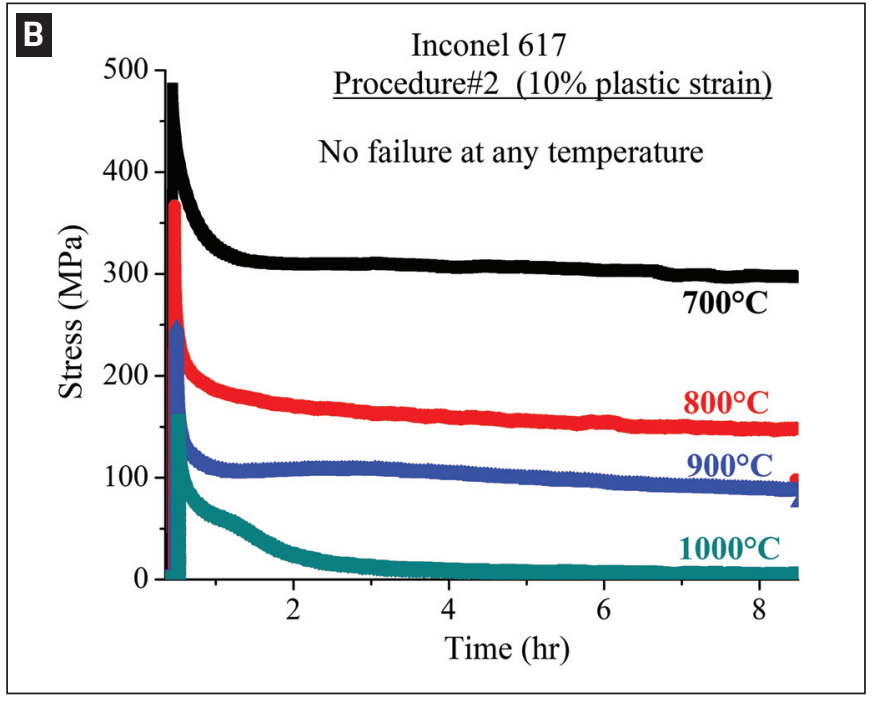

D

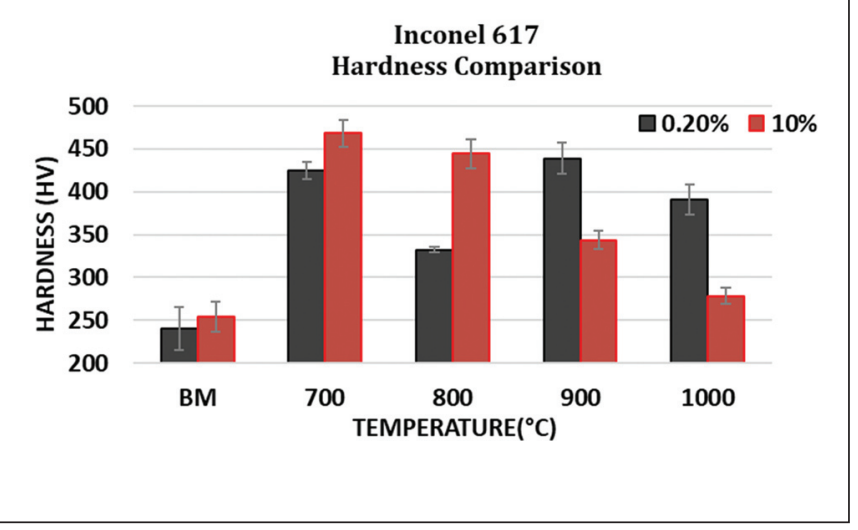

Fig. $9-A-$ Stress vs. time plot for Incone ${ }^{\circledR} 617$ with procedure 1 ( $0.2 \%$ plastic strain); B - stress vs. time plot for Inconel ${ }^{\circledR} 617$ with procedure 2 (10\% plastic strain); C - ductility vs. temperature for both procedures 1 and 2 for Inconel ${ }^{\circledR} 617 ; D-$ hardness at $^{-}$ fracture vs. temperature for both procedures 1 and 2 for Inconel ${ }^{\circledR} 617$.

this study. The aim here was to develop an SRC susceptibility index including all the alloys with their respective level of susceptibility, moving beyond a simple pass/fail type classification of SRC susceptibility. To rank the SRC susceptibility of a wide range of alloys under varied test conditions, a unified number associated with SRC susceptibility was developed. The SP values were combined with concepts of the Risk Priority Number (RPN) (Refs. 24, 25). The RPN is a tool in failure modes and effect analysis (FMEA) used for risk assessment of various critical modes of failure for any design or process. RPN is a dynamic tool that can be applied to simple processes such as baking to complicated manufacturing of a critical component on an aircraft. RPN can be calculated to identify and prioritize the potential failure modes. With this established approach, a numerical value is assigned to all the failure modes, based on which corrective measures are prioritized. RPN is expressed as the product of the occurrence, severity, and detectability for that failure mode, shown in Equation 1:

$$
R P N=\text { Occurence } * \text { Severity } * \text { Detectability }
$$

In Equation 1, occurrence is the frequency of a failure mode to occur during the process. It is assigned a value from one to ten, where higher numbers indicate more frequent failures (e.g., a value of one for occurrence indicates that the failure mode does not occur at all). Severity is the impact of that failure mode on the process performance. Severity is also assigned a value between one to ten, where ten implies a complete impairment of the process due to that failure mode. Thus, the lower the severity value, the smaller the effect of the failure mode on the process outcome. The detectability value (also assigned values from one to ten) is the ease of detecting the failure mode (Refs. 24, 25) where higher values indicate that the failure mode is difficult to detect. For detectability, a value of ten relates to a failure mode that is not detectable during the process. Hence, for each failure mode, the maximum value of RPN can be 1000, which represents a potential failure that occurs every time the process is conducted, completely stops a process, and cannot be detected. Therefore, a failure mode with higher RPN is placed higher on the priority chart.

The RPN concepts described above were used in similar fashion to develop a susceptibility number (SN) for all the SRC tests, such that a higher $S N$ relates to a higher SRC susceptibility. The value of $\mathrm{SN}$ is given by Equation 2, where $\mathrm{SP}_{\mathrm{n}}$ repre- 



Fig. 10 - Fracture modes: A - Type I: Intergranular with smooth grain facets [Grade $22 \mathrm{~V}, 600^{\circ} \mathrm{C}, 0.2 \%$ ]; B - Type II: Intergranular with MVC on grain facets [Grade $22 \mathrm{~V}, 700^{\circ} \mathrm{C}, 0.2 \%$ ]; C - Type III: Mixed intergranular and ductile micro-voids [Haynes $230,800^{\circ} \mathrm{C}$, 10\%]; D - Type IV: Ductile MVC [347H, $800^{\circ} \mathrm{C}, 0.2 \%$ ].

sents the six susceptibility parameters from $\mathrm{SP}_{1}$ to $\mathrm{SP}_{6}$ for each SRC test, namely, ductility, percentage stress relaxed, increase in hardness at fracture (compared to base metal), failure time, fracture mode and secondary cracks below the fracture. Severi$t y_{n}$ and Detectability ${ }_{n}$ are, respectively, the severity and detectability values for each $\mathrm{SP}_{\mathrm{n}}$ as discussed below.

$$
S N=\sum_{S P_{0}}^{S P_{6}}\left(S P_{n} * \text { Severity }_{n} * \text { Detectability }_{n}\right)
$$

The assigned values of severity and detectability for all the SP are listed in Table 4. It is recognized that these values are somewhat subjective; however, with logical rationale for assigning the values, the extent of subjective nature can be reduced. Furthermore, results of a sensitivity analysis (discussed below) show that reasonable variations to the parameters have minimal effect on the susceptibility ranking results, thus demonstrating the robustness of the approach. The rationale for assigning values of severity and detectability are discussed next.

A stronger indicator to SRC susceptibility was assigned a higher severity value (maximum of 10). For example, the type of fracture mode is a stronger indicator as compared to hardness increase at fracture because IG fracture highlights SRC susceptibility irrespective of the alloy system. However, the increase in hardness near fracture is an inherent property of an alloy and can be due to both precipitation strengthening and/or work hardening. Detectability was defined as the confidence in the measured value of an SP. For example, the time to failure can be accurately measured in the Gleeble ${ }^{\circledR}$ and thus, was assigned a higher value as compared to the subjective parameters like fracture mode.

The fracture mode and secondary cracks are both qualitative parameters, hence, cannot be used directly in the SN calculation. Therefore, the major fracture modes and secondary crack types classified earlier (shown in Figs. 10 and 11 , respectively) were assigned values out of ten shown in Table 5, where a higher number indicates higher SRC susceptibility. The other SP values were also expressed out of ten for consistency. The SP values for percent hardness increase were calculated by simply dividing the experimentally calculated value by ten. The SP values for ductility, failure time, and stress relaxed (all values expressed as percentages) were calculated using the simple relation given by Equation 3 . The complementary values of the three SP values (as calculated by Equation 3) were used in the SN calculation and 

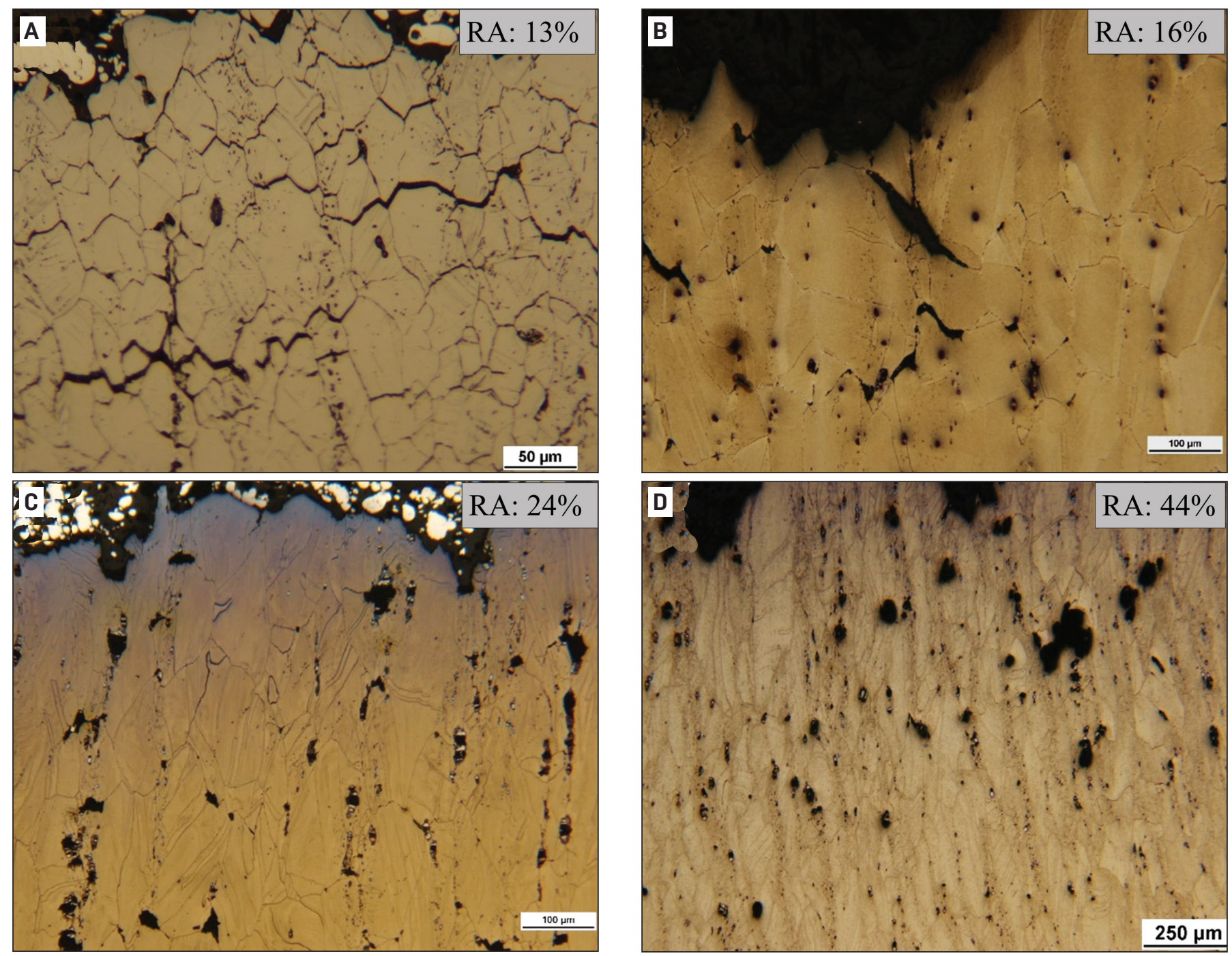

Fig. 11 - Secondary cracks: A - Type I: Intergranular cracks with no deformed grains [347H, $\left.800^{\circ} \mathrm{C}, 10 \%\right]$; B - Type II: Intergranular cracks with deformed grains [Haynes $282,900^{\circ} \mathrm{C}, 10 \%$ ]; C - Type III: Mixed inter- and intra-granular cracks [In $\left.617,800^{\circ} \mathrm{C}, 10 \%\right]$; D Type IV: Trans-granular ductile voids [In $\left.617,1000^{\circ} \mathrm{C}, 0.2 \%\right]$.

not the values themselves because these SP hold an inverse relation with SRC susceptibility. For example, a higher value of ductility, percentage stress relaxed, or failure time indicate lower SRC susceptibility but result in a higher SN.

Therefore, using the complementary values for these SP will maintain the direct relation to both SRC susceptibility and SN.

$$
S P_{n}=\left(100-S P_{n}\right) / 10
$$

For simplicity of plotting, the SN values (calculated using Equation 2) for the entire spectrum of samples and test conditions was normalized to the highest value in the series and multiplied by 100. Figure 12 summarizes the SN values for all the alloys and test conditions. As summarized by the table in Fig. 12, the susceptibility chart is divided into three major regions, namely, susceptible, moderately susceptible, and resistant to SRC. The alloys and test conditions in one region of the susceptibility chart share a common trend in terms of the SP values. For example, in the susceptible re- gion, all the samples failed during the test, had Type I or II fracture mode, Type I secondary cracks, generally low ductility $(<10 \%)$, significant hardening at the fracture, and low percent of stress relaxed $(<20 \%)$. The similar trends of the other regions are listed in the table in Fig. 12. There is a rather sharp demarcation (i.e., reduction in $\mathrm{SN}$ value) of susceptible test conditions with the conditions that are only moderately susceptible. This reduction in $\mathrm{SN}$ is associated not only with the failure of alloys during the test, but is a result of a combination of all the six measures of SRC susceptibility. For example, Grade 22 at $600^{\circ} \mathrm{C}$ with $0.2 \%$ plastic strain, failed in $30 \mathrm{~min}$, had low ductility of $5 \%$, high hardening at fracture, and low-stress relaxation with Type I fracture mode and secondary cracks.

As highlighted earlier, the severity and detectability values for each SP were subjective to a certain extent. Therefore, to check for the robustness of the ranking methodology, a sensitivity test was performed. Severity and detectability values were iteratively varied in the range as shown in Table 4, while other values were not altered from the stan- 


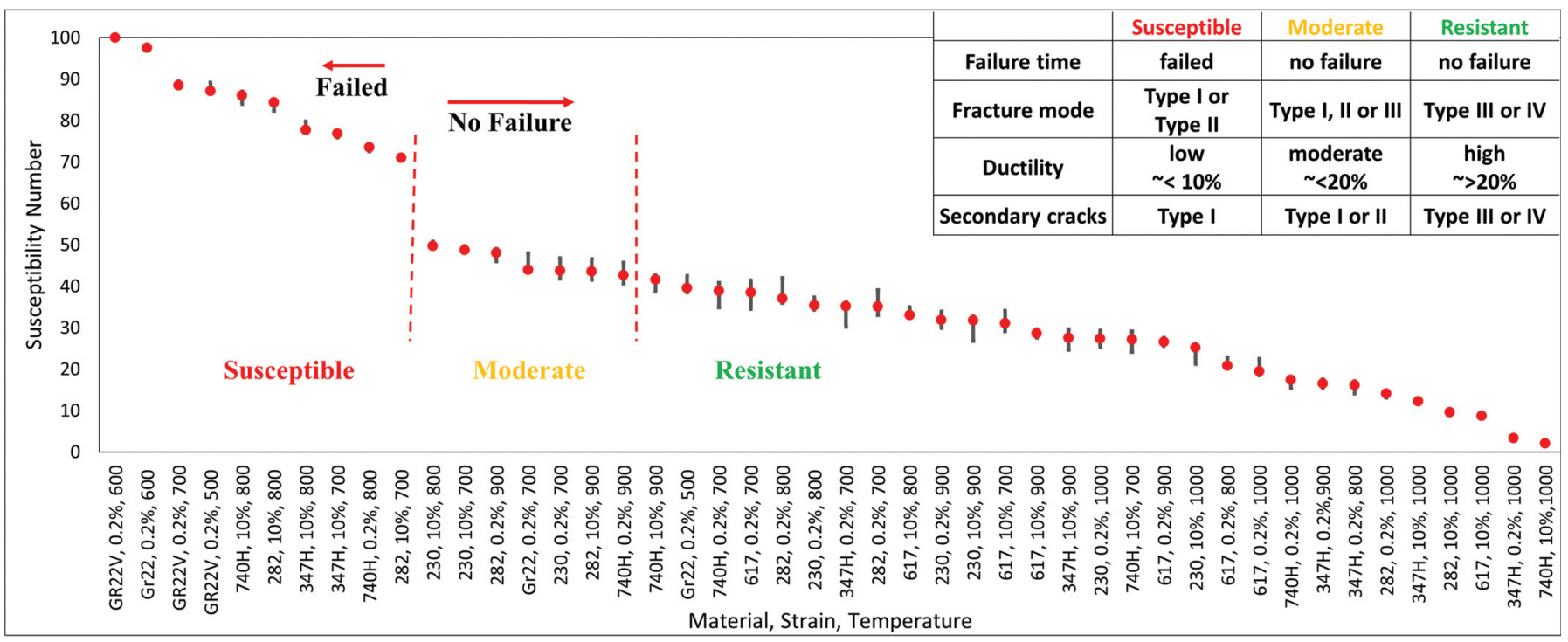

Fig. 12 - SRC susceptibility ranking chart encompassing all the alloys and test conditions. Error bars highlight the change in ranking during sensitivity analysis.

dard value. A total of 62 combinations were analyzed and the change in rank was noted with each variation of values. The error bars in Fig. 12 show the maximum change in ranking both above and below the standard position of all the conditions reported earlier. Note that no meaningful change in ranking was observed for the susceptible region, beginning of the moderately susceptible region, and the end of the resistant region of the chart. The change in ranking was localized mainly around the border between moderately susceptible and resistant regions. This localization can be attributed to very close SN values for these test conditions. The insignificant change in ranking confirms the robustness of the ranking methodology.

\section{Microstructural Characterization}

The ferritic alloys in this study were primarily included to validate the SRC test procedures. Grades 22 and $22 \mathrm{~V}$ have been widely reported in literature to be susceptible to SRC, and the cracking mechanisms are generally understood (Refs. 26-32). Thus, microstructural characterization stud- ies were aimed at the remaining austenitic alloys.

Inconel $740 \mathrm{H}$ is a $\gamma^{\prime}$ strengthened alloy that also forms $\mathrm{M}_{23} \mathrm{C}_{6}$, MC, G-phase, and $\eta$ (Refs. 9, 33-35). This alloy showed high and moderate susceptibility to SRC at $800^{\circ}$ and $900^{\circ} \mathrm{C}$, respectively with the application of both 0.2 and $10 \%$ plastic strain - Fig. 12. Other test conditions for $740 \mathrm{H}$ were resistant to SRC. Therefore, the two test conditions with $0.2 \%$ plastic strain $\left(800^{\circ}\right.$ and $\left.900^{\circ} \mathrm{C}\right)$ were selected for microstructural characterization. Figure $13 \mathrm{~A}$ and $\mathrm{B}$ shows the fracture surface of the sample tested at $800^{\circ} \mathrm{C}$. Note that the fracture mode is intergranular with MVC confined to the boundary regions - Fig. 13A and B. This indicates that plastic deformation was localized along the grain boundaries. Closer examination of the grain boundaries (Fig. 14A and B) show the presence of precipitate-free zones (PFZs) associated with a lamellar precipitate morphology. EDS results from the matrix and coarsened secondary phase are shown in Fig. 14B.

The secondary phase is slightly enriched in $\mathrm{Nb}, \mathrm{Al}$, and $\mathrm{Ti}$ and exhibits slight depletion in Cr. It is recognized that these elemental concentrations (table in Fig. 14B) are not strictly from the precipitates, but also sample the surround-

Table 5 - Marking Scheme for Qualitative Parameters for Different Modes

Parameter 5: Fracture Mode

Type I

Type II

Type III

Type IV
Description

IG with smooth grains

IG with MVC on grain facets

Mixture of IG and MVC

Ductile MVC
Value

10

10

5

0
Parameter 6: Secondary Cracks Type I

Type II

Type III

Type IV
Description

IG with no deformed grains

IG with deformed grains

Mixture of IG and trans-granular

Ductile voids
Value

10

5

2.5

0 

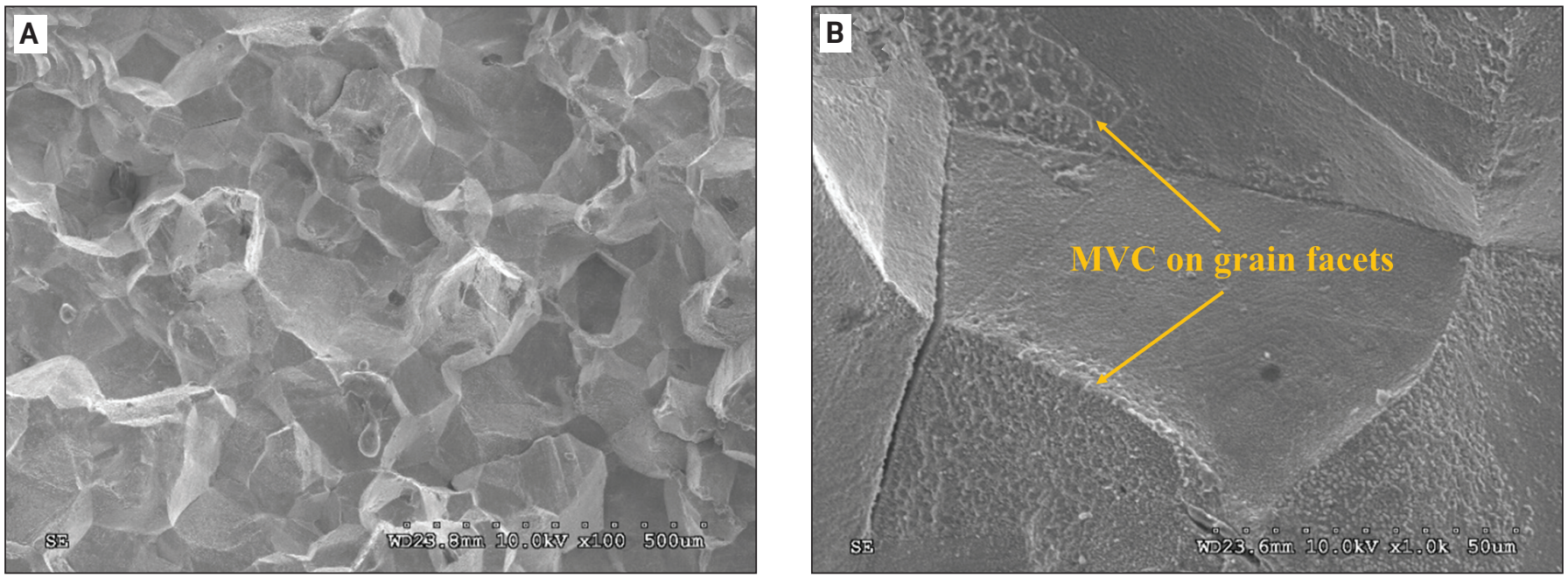

Fig. $13-740 \mathrm{H}\left(0.2 \%, 800^{\circ} \mathrm{C}\right)$ : A - Intergranular fracture mode; $\mathrm{B}$ - fracture surface at high magnification showing microvoids on grain facets.

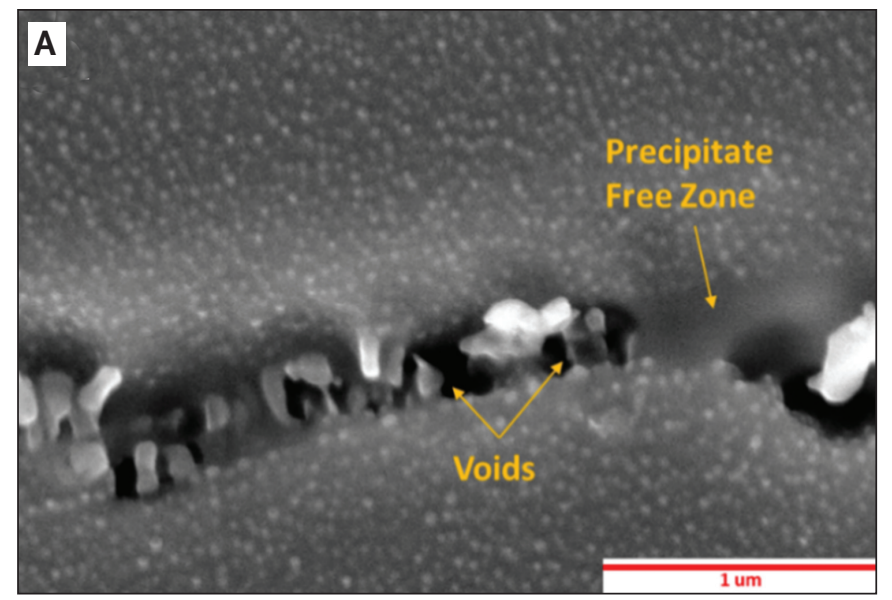

Fig. $14-740 \mathrm{H}\left(0.2 \%, 800^{\circ} \mathrm{C}\right)$ : A - Grain boundary with discontinuous precipitates and voids associated with PFZ; $B-E D S$ line-scan across grain boundary with discontinuous precipitates showing higher Al concentration within the DP region.

ing matrix as the electron beam interaction depth (calculated using the Monte-Carlo ${ }^{\circledR}$ simulation) was approximately $280 \mathrm{~nm}$ with lateral spatial resolution of approximately 260 $\mathrm{nm}$. However, the composition results and observed lamellar morphology can be combined with information previously reported on secondary phases as an aid to identify the lamellar grain boundary phase. Of the previously reported stable phases in $740 \mathrm{H}$, G-phase only forms after long-term aging (beyond $2500 \mathrm{~h}$ ) (Ref. 8), and $\eta$ forms in a needle-like morphology after about $100 \mathrm{~h}$ at $800^{\circ} \mathrm{C}$ (Ref. 36). Thus, these phases would not be expected to form under the short test times in this study. The observed depletion in $\mathrm{Cr}$ and the presence of $\mathrm{Ni}$ and $\mathrm{Al}$ also rule out the possibility of $\mathrm{M}_{23} \mathrm{C}_{6}$ or $\mathrm{MC}$, as the solid solubility of $\mathrm{Ni}$ and $\mathrm{Al}$ is known to be negligible in both the phases (Refs. 8, 33), which is also validated from phase fraction calculations using ThermoCalc ${ }^{\circledR}$ (Table 6). In addition, the formation of $\gamma^{\prime}$ in IN740H with the same lamellar morphology has recently been reported by Bechetti et al. in this alloy, and is consistent with the higher $\mathrm{Nb}, \mathrm{Ti}$, and $\mathrm{Al}$ concentrations. Therefore, $\gamma^{\prime}$

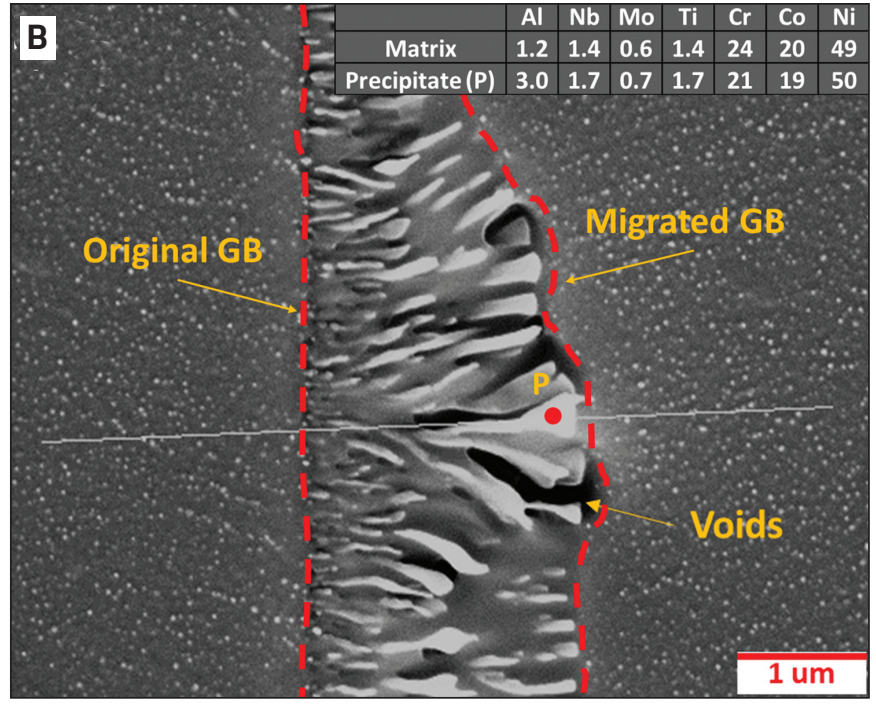

$\left[\mathrm{Ni}_{3}(\mathrm{Ti}, \mathrm{Al}, \mathrm{Nb})\right]$ is the only phase that is consistent with the XEDS and morphology observations.

The lamellar morphology shown in Fig. 14 can occur due to discontinuous precipitation or coarsening (Refs. 37-43). In the current study, continuous precipitation was observed on the grain boundaries with no lamellar precipitates, suggesting that nucleation was not associated with the lamellar morphology. Thus, the detrimental lamellar precipitate morphology associated with stress relief cracking at $800^{\circ} \mathrm{C}$ in this alloy forms by discontinuous coarsening, and this is consistent with previous studies on this alloy (Refs. 33, 35). The presence of coarse grain boundary precipitates that form by discontinuous reactions are known to degrade mechanical properties by promoting premature IG fracture (Refs. 33, 44, 45). For example, Bechetti et al. have recently shown that this morphology is associated with premature creep failure in welds on IN740H (Ref. 33). Considering the known similarities of deformation mechanisms between creep damage and stress relief cracking (Refs. 16, 46), the detrimental effect of the coarsened grain boundary $\gamma^{\prime}$ phase on stress relief cracking is not surprising.

IN740 H tested at $900^{\circ} \mathrm{C}$ did not fail during the test but 


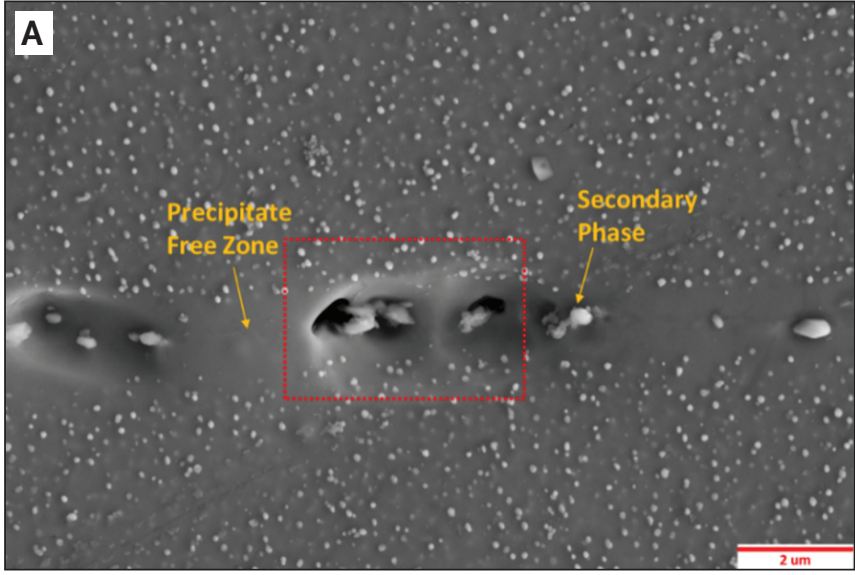

Fig. $15-740 \mathrm{H}\left(0.2 \%, 900^{\circ} \mathrm{C}\right): \mathrm{A}-\mathrm{GB}$ precipitate and voids associated with symmetric PFZ formation; $B$ - EDS map of the highlighted region showing $\mathrm{Nb}, \mathrm{Ti}, \mathrm{C}$ enrichment and $\mathrm{Al}$ depletion.

showed IG fracture with low ductility when pulled to failure and is thus considered as moderately susceptible. The slight increase in ductility and reduction in hardness at $900^{\circ} \mathrm{C}$ (Fig. 5D) compared to $800^{\circ} \mathrm{C}$ may have attributed to the reduced $\gamma^{\prime}$ content and coarsening of $\gamma^{\prime}$ precipitates. Although void formation at the grain boundary is associated with the presence of PFZs, the mechanism of PFZ formation is different at this temperature. The XEDS elemental map (Fig. 15B) shows the $\mathrm{GB}$ precipitates to be rich in $\mathrm{Nb}$, Ti, and $\mathrm{C}$ while

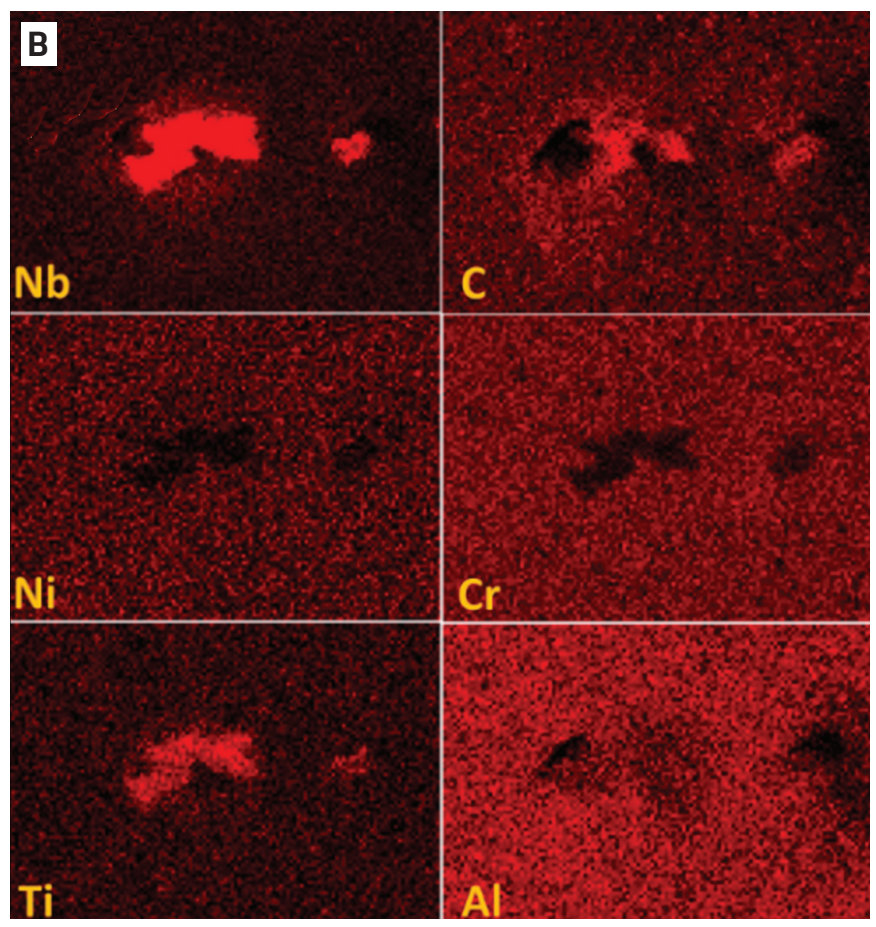

depleted in $\mathrm{Ni}, \mathrm{Cr}$, and $\mathrm{Al}$. This indicates that the grain boundary phase is a $(\mathrm{Nb}, \mathrm{Ti}) \mathrm{C}$ carbide, which is consistent with other studies on $740 \mathrm{H}$ (Refs. 9, 33). The $\gamma^{\prime}$ solvus for IN740H is between $900^{\circ}$ and $1000^{\circ} \mathrm{C}$ (Ref. 9), while that for $\mathrm{NbC}$ is around $1100^{\circ}$ to $1200^{\circ} \mathrm{C}$ (Ref. 9). Therefore, at

Table 6-Calculated Composition of $\gamma^{\prime}$ and MC at Different Temperatures for $740 \mathrm{H}$

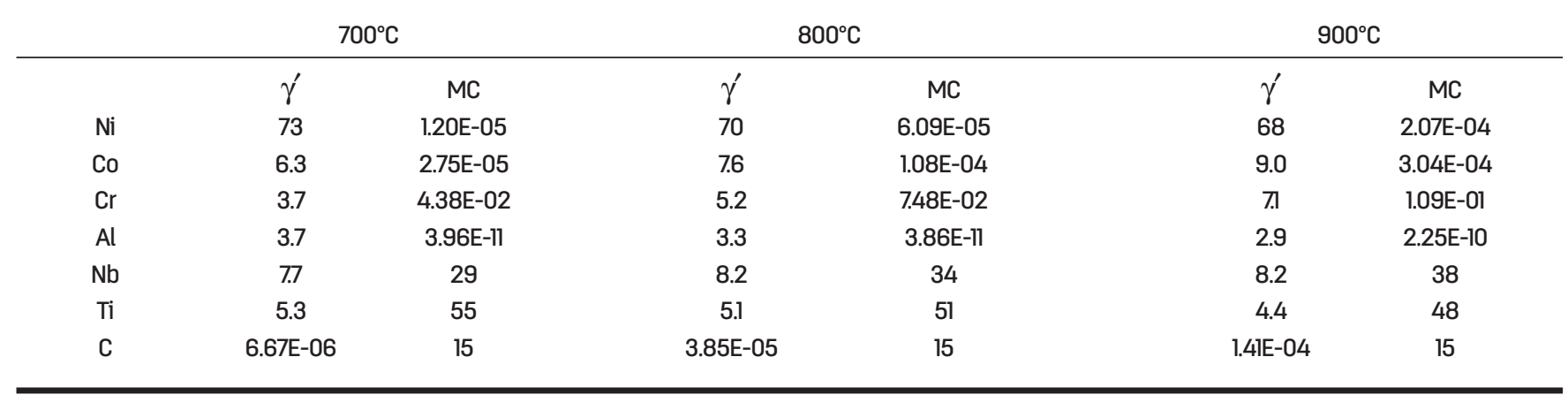

*Values are reported in wt-\%.

Table 7-Calculated Composition of Stable Phases for Haynes 282

\begin{tabular}{ccccc} 
& Gamma & Gamma Prime & $M_{6} \mathrm{C}$ & $\mathrm{M}_{23} \mathrm{C}_{6}$ \\
\hline $\mathrm{Ni}$ & 55 & 78 & 25 & 3.1 \\
$\mathrm{Co}$ & 12 & 3.9 & 0.8 & 0.8 \\
$\mathrm{Cr}$ & 23 & 1.3 & 17 & 7.5 \\
$\mathrm{Al}$ & 0.6 & 6.0 & 0.0 & 0.0 \\
$\mathrm{Mo}$ & 8.9 & 0.3 & 53 & 19.4 \\
$\mathrm{Ti}$ & 0.2 & 10 & 0.0 & 0.0 \\
$\mathrm{C}$ & 0.0 & 0.0 & 2.7 & 5.2 \\
\hline
\end{tabular}

*Values are in wt-\% calculated over $700^{\circ}$ to $900^{\circ} \mathrm{C}$.

${ }^{*} \mathrm{M}_{23} \mathrm{C}_{6}$ calculated over $800^{\circ}$ to $900^{\circ} \mathrm{C}$. 

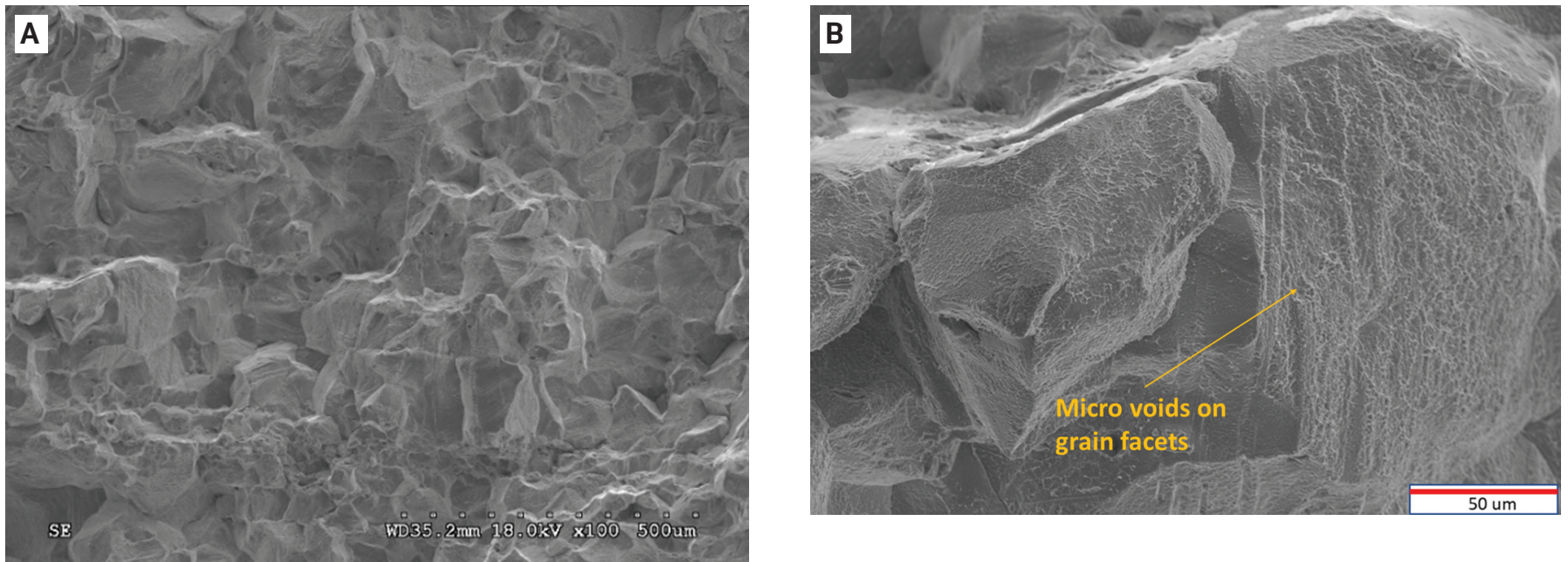

Fig. 16 - Haynes ${ }^{\circledR} 282\left(10 \%, 700^{\circ} \mathrm{C}\right)$ : A - SEM fractograph showing Intergranular fracture mode; B - MVC on grain facets.
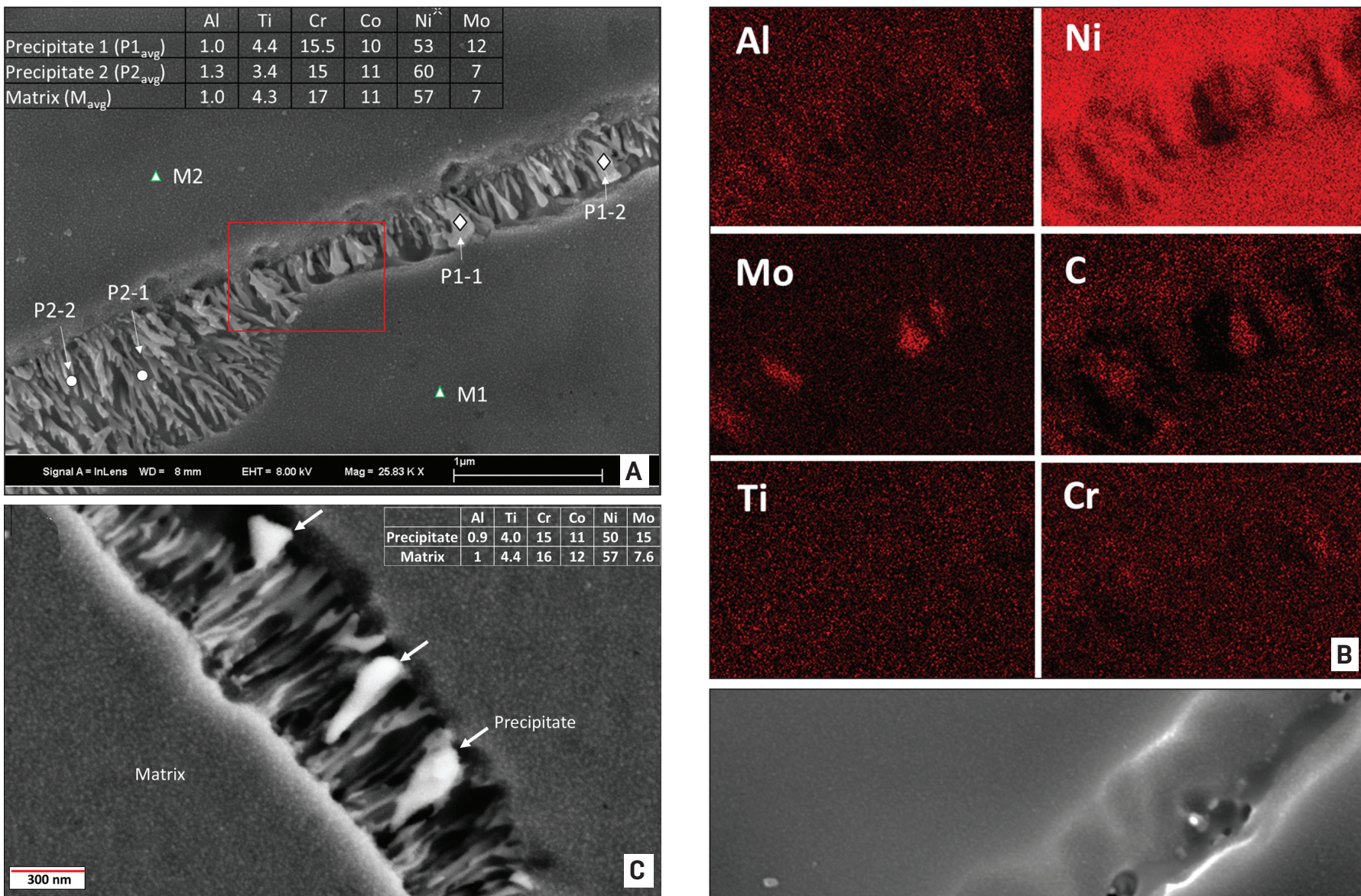

Fig. 17 - Sample A, B: Haynes ${ }^{\circledR} 282\left(10 \%, 700^{\circ} \mathrm{C}\right):$ A - Discontinuous precipitation at the grain boundary with summarized XEDS spot scan results; $B-X E D S$ elemental map of the highlighted region from A. Sample C, D: Haynes ${ }^{\circledR} 282(10 \%$, $800^{\circ} \mathrm{C}$ ): $\mathrm{C}$ - discontinuous precipitation and associated voids forming along grain boundaries with summarized XEDS results; $D$ - precipitate free zone at the grain boundary with coarsened precipitates and associated voids.

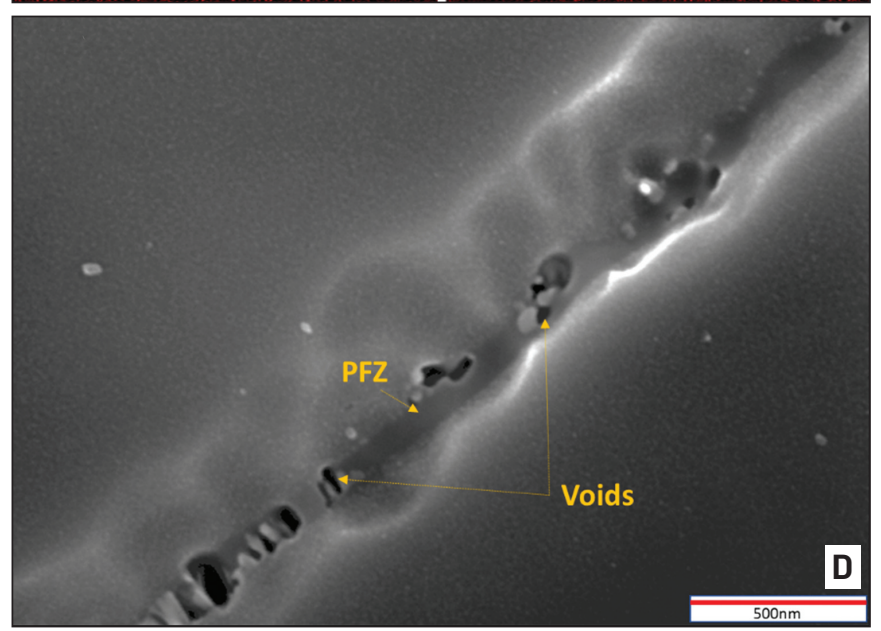



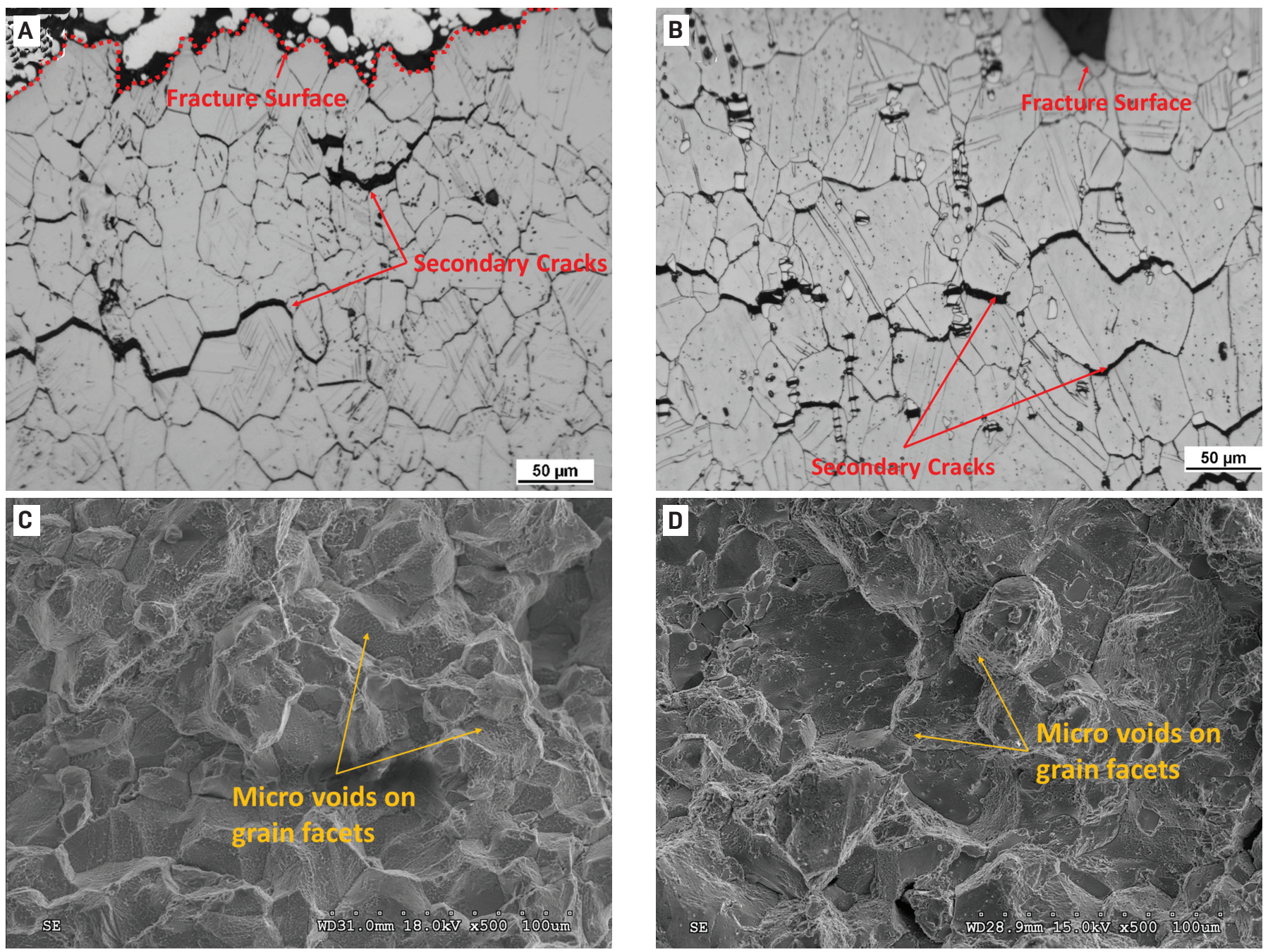

Fig. 18 - In A, B: Light optical images showing sharp IG cracks below fracture: $\mathrm{A}-347 \mathrm{H}, 10 \%, 700^{\circ} \mathrm{C} ; \mathrm{B}-\mathrm{Haynes}^{\circledR} 230,10 \%, 700^{\circ} \mathrm{C}$.

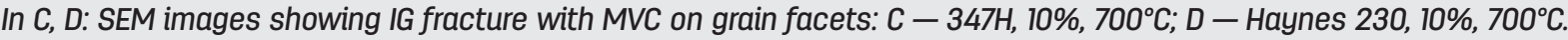

$900^{\circ} \mathrm{C},(\mathrm{Nb}, \mathrm{Ti}) \mathrm{C}$ will grow at the expense of $\gamma^{\prime}$. Growth of the grain boundary $(\mathrm{Nb}, \mathrm{Ti}) \mathrm{C}$ will cause localized depletion of $\mathrm{Nb}$ and $\mathrm{Ti}$ in the grain boundary regions, thus leading to localized dissolution of $\gamma^{\prime}$ and associated formation of the PFZ. These microstructural features in the samples tested at $800^{\circ}$ and $900^{\circ} \mathrm{C}$ account for the SRC susceptibility observed at these temperatures.

Haynes 282 is also a $\gamma^{\prime}$ strengthened alloy and forms other phases such as $M_{23} C_{6}, M C$, and $M_{6} C$ (Refs. 9, 47, 48). The composition of the phases was calculated using ThermoCalc ${ }^{\circledR}$, listed in Table 7. MC was calculated to be stable above $1000^{\circ} \mathrm{C}$. Although sigma phase is thermodynamically stable, it only forms after long-term aging at $800^{\circ} \mathrm{C}$ (Refs. 9, 49) and hence is unlikely to form in the 8-h SRC test. From Fig. 12, Haynes 282 is susceptible to SRC only after the application of $10 \%$ plastic strain at $700^{\circ}$ and $800^{\circ} \mathrm{C}$. These samples were selected for the microstructural investigation.

Figure 16A shows the intergranular fracture mode in the sample tested at $700^{\circ} \mathrm{C}$ with localized ductility (MVC) on the grain facets - Fig. 16B. Figure 17 shows the grain boundary features that were typical at both $700^{\circ}$ and $800^{\circ} \mathrm{C}$. The matrix contains finely dispersed $\gamma^{\prime}$ (Fig. 17C) while the grain boundaries show precipitates formed by discontinuous coarsening - Fig. 17A, C. Precipitate-free zones are also observed at $800^{\circ} \mathrm{C}$ (Fig. 17D). The secondary phase (Fig. 17B) is rich in Mo and slightly depleted in Ni relative to the matrix. From Table 7, note that the $\mathrm{M}_{6} \mathrm{C}$ phase is enriched in $\mathrm{Mo}$ and depleted in Ni (relative to the matrix). The $\mathrm{M}_{23} \mathrm{C}_{6}$ phase is also stable and exhibits Mo enrichment, but also has a very high $\mathrm{Cr}$ concentration that is not consistent with the XEDS results. Grain boundary precipitation of $\mathrm{Cr}$-rich $\mathrm{M}_{23} \mathrm{C}_{6}$ leading to creep failure has been reported in Haynes 282 (Ref. 50). However, no prominent $\mathrm{Cr}$-enriched phase was detected in the current study, which is likely due to the short aging times involved $(8 \mathrm{~h})$. This is consistent with the slow precipitation kinetics of $\mathrm{M}_{23} \mathrm{C}_{6}$ reported in Haynes 282 (Refs. 47, 48). As with IN740H, the cracking observed in Haynes 282 also appears to be associated with discontinuous coarsening and formation of precipitate-free zone.

Haynes 230 is a solid solution strengthened alloy, and $347 \mathrm{H}$ is a stainless steel that is strengthened primarily by $\mathrm{NbC}$. When tested at $700^{\circ} \mathrm{C}$ with $10 \%$ strain, $347 \mathrm{H}$ was susceptible while Haynes 230 exhibited moderate cracking susceptibility - Fig. 12. As shown in Fig. 18, each of these 


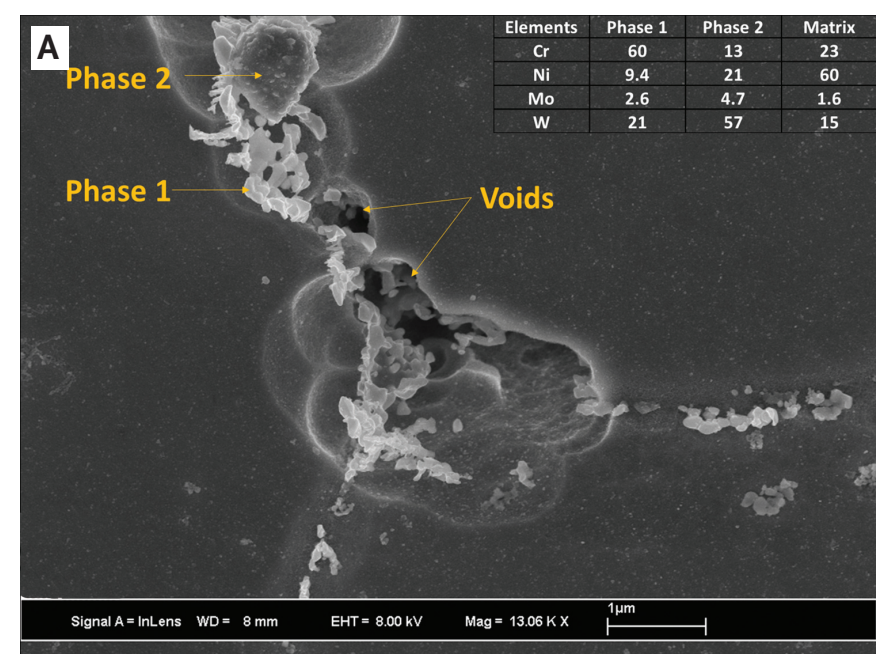

Fig. 19 - SEM micrograph of Haynes $230,10 \%, 700^{\circ} \mathrm{C}$ : A Voids at the grain boundaries associated with IG $\mathrm{Cr}$ and Wrich precipitates; $B$ - discontinuous precipitates and associated voids; $\mathrm{C}-\mathrm{SEM}$ micrograph of $347 \mathrm{H}, 10 \%, 700^{\circ} \mathrm{C}$ showing voids at the grain boundaries with no apparent PFZ.

alloys exhibited sharp intergranular cracks below the fracture surface with no significant signs of plastic deformation, and the fracture mode was intergranular with localized MVC along the grain boundaries. $\mathrm{M}_{23} \mathrm{C}_{6}$ and $\mathrm{M}_{6} \mathrm{C}$ are the major precipitates reported in Haynes 230 (Refs. 51, 52). In this study, a Cr-rich phase was observed to precipitate in both discontinuous and interconnected chain-like morphology along with blocky W-rich phase (Fig. 19A, B). Discontinuous coarsening of $\mathrm{M}_{23} \mathrm{C}_{6}$ has been extensively reported to cause $\mathrm{GB}$ weakening and creep failure in Haynes 230 and similar alloy systems (Refs. 52-54). Interconnected $\mathrm{M}_{23} \mathrm{C}_{6}$ morphology are also reported to lower the ductility and tensile strength in similar Ni-Cr-W alloys causing fracture (Ref. 54). Even though no apparent PFZ was observed, the GB coarsening of $\mathrm{Cr}$-rich phase can locally deplete the matrix in both $\mathrm{Cr}$ and $\mathrm{W}$, thereby forming a locally softened region. Therefore, GB weakening by $\mathrm{M}_{23} \mathrm{C}_{6}$ precipitation and coarsening is the likely reason for higher cracking susceptibility in Haynes 230.

The $\mathrm{NbC}$ precipitates in Alloy $347 \mathrm{H}$ form within the matrix preferentially on dislocations and significantly strengthen the matrix (Refs. 55-58). The precipitates are known to be very fine, in the range of 20 to $40 \mathrm{~nm}$ (Ref. 59) and therefore cannot typically be resolved in the SEM. Although voids are observed on the grain boundaries/grain facets (fracture surface Fig. 18C), no apparent PFZs were observed during examination by SEM — Fig. 19C. Transmission electron microscopy techniques are required to investigate the possibility of PFZs and clarify their potential role in stress relief cracking in this alloy. In previous work, very fine $\mathrm{NbC}$ precipitates are reported to form at $700^{\circ}$ and $800^{\circ} \mathrm{C}$ with the lowest coarsening rate as compared to higher temperatures (Ref. 59). Fine, dispersed precipitates impart higher strengthening to the material than coarse precipitates (Ref. 12); therefore, the matrix strengthening from $\mathrm{NbC}$ is highest at $700^{\circ}$ and $800^{\circ} \mathrm{C}$. Note that this sample (that was tested at $700^{\circ} \mathrm{C}$ ) exhibited the highest increase in hardness, which is also consistent with dense $\mathrm{NbC}$ precipitation. This high matrix strength (and the possible for-
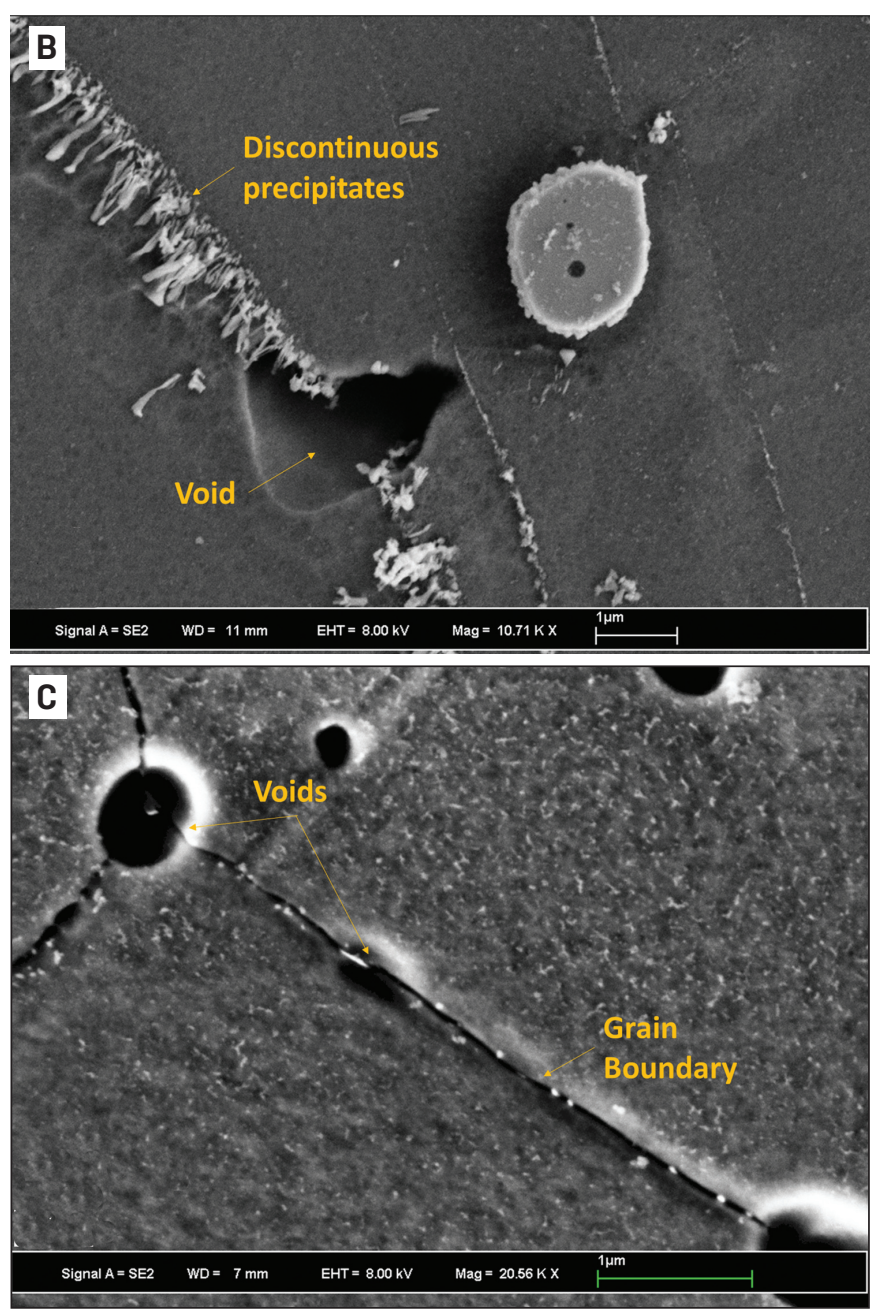

mation of PFZs) may account for the observed cracking susceptibility in this alloy.

Inconel 617 is a solid solution strengthened alloy and was resistant to SRC at all test conditions - Fig. 12. The alloy exhibited a ductile fracture mode (Fig. 20A) with elongated grains below the fracture (Fig. 20B) that suggests high plasticity. Discrete voids with no IG cracks were observed below the fracture (Fig. 20B). Secondary phases form locally along regions that appear to be associated with remnant segregation from solidification, subsequently rolled to form parallel bands. Voids formed due to the rupturing of second phases under stress Fig. 20C. The stable phases reported for Inconel 617 were $\mu, \mathrm{M}_{6} \mathrm{C}, \mathrm{MX}, \gamma^{\prime}$, and $\mathrm{M}_{23} \mathrm{C}_{6}$ (Ref. 60). Both interand intra-granular Mo and $\mathrm{Cr}$-rich second phases were observed from the XEDS scans (table in Fig. 20C). The above analysis was done on samples with a base metal grain size of $85 \mu \mathrm{m}$ (Table 3). A second heat of Inconel 617 with inherently larger grains (base metal grain size of $135 \mu \mathrm{m}$ ) was also considered to investigate the influence of the grain size in the HAZ, since larger HAZ grain sizes are known to promote increased susceptibility to SRC (Refs. 3, 5). Samples from this base metal were held at a peak temperature $\left(1225^{\circ} \mathrm{C}\right)$ for various times to maximize grain coarsening (Fig. 21). No significant coarsening was observed after a $30 \mathrm{~s}$ hold up to $10 \mathrm{~min}$, possibly due to blocky second phases (as in Fig. 20C) acting as inhibitors for GB migration necessary 

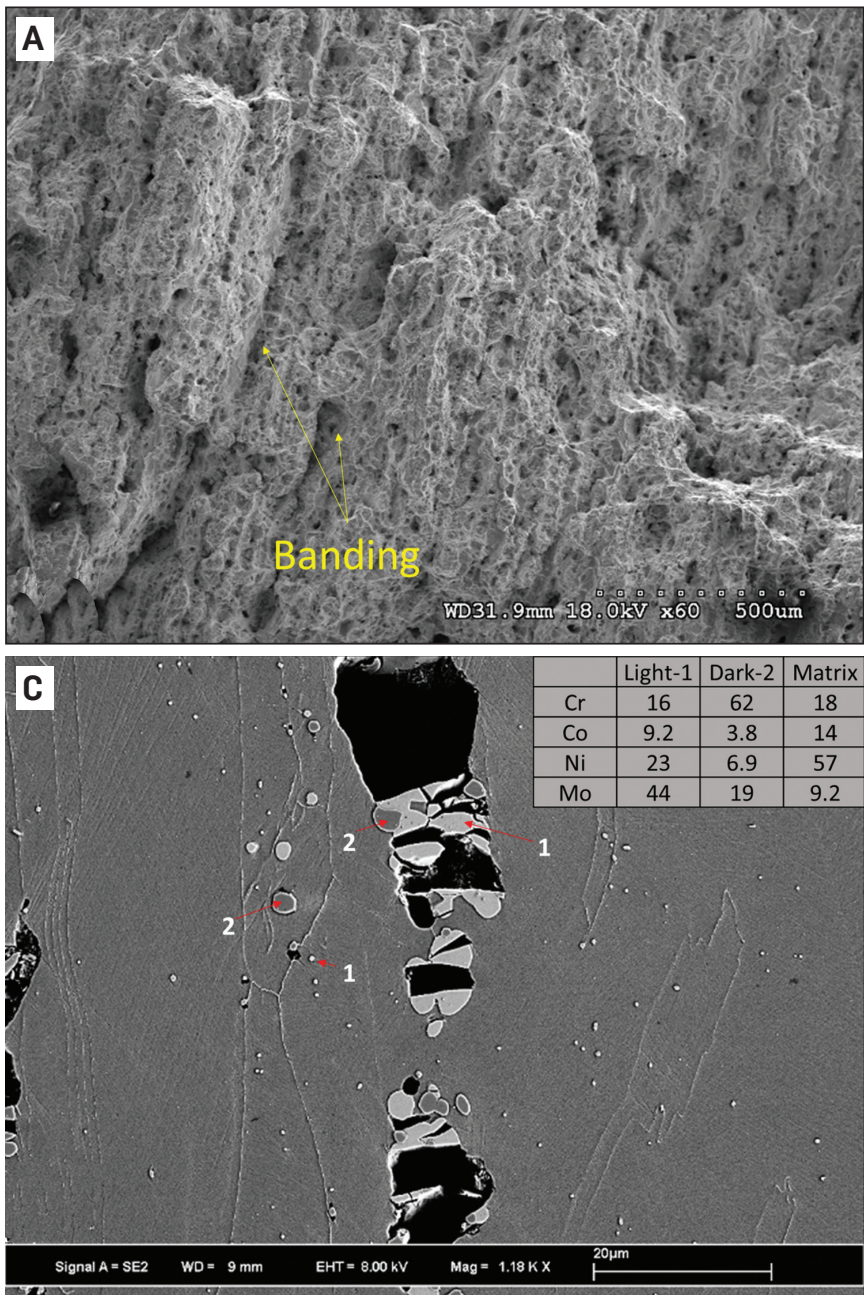

Fig. 20 - Inconel ${ }^{\circledR} 617\left(10 \%, 900^{\circ} \mathrm{C}\right)$ : A - SEM fractograph showing ductile fracture mode with MVC; B - LOM image of longitudinal cross section below fracture showing voids associated with bands of second phase; $C$ - ruptured second phases and associated voids; (table) XEDS results for second phases.

for coarsening. Therefore, coarsened grain samples with a 60-s hold were tested for SRC susceptibility (Fig. 22A-D) at $700^{\circ}$ and $800^{\circ} \mathrm{C}$ (PWHT temperature) with both 0.2 and $10 \%$ plastic strain. For comparison, Heat 1 and 2 test results were overlaid in Fig. 22 and showed no failure during the test for all the test conditions. The stress relaxation plots were similar for both the heats, especially for the coldworked samples (Fig. 22C and D), possibly due to recrystallization facilitated by prior deformation. Increased stress relaxation was observed at $700^{\circ} \mathrm{C}$ with $0.2 \%$ plastic strain (Fig. 22A) for sample with coarsened grains, suggesting considerable inherent ductility in the material to accommodate stress through plastic deformation. When pulled to failure at the end of the test, all the samples failed in a ductile MVC mode. Thus, Inconel 617 was found to be resistant to SRC (during PWHT) with a range of grain sizes. However, it is known that long term aging of Inconel 617 can considerably lower the ductility and promote IG fracture by $\gamma^{\prime}$ precipitation and concomitant coalescing of GB carbides to form a film morphology (Ref. 61). This suggests that this alloy can
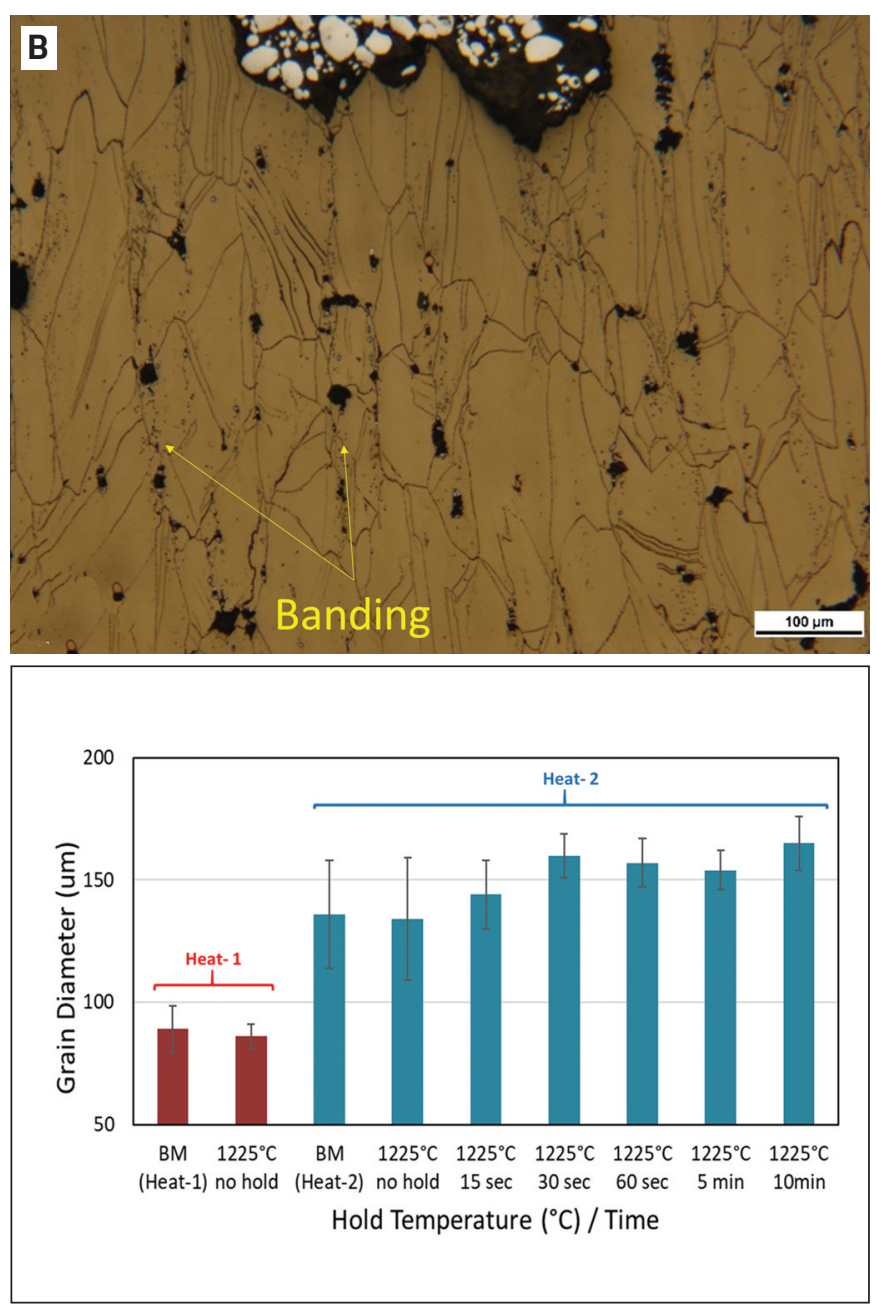

Fig. 21 - Chart showing the variation in grain size for two different heats of Inconel ${ }^{\circledR} 617$ with different hold times at the peak temperature.

be susceptible to strain age cracking (SAC) during long-term service but appears to be resistant to cracking during the short times associated with PWHT.

These results indicate that SRC typically forms under the combined effect of matrix strengthening and concomitant grain boundary weakening. The respective contribution of matrix strengthening, and grain boundary weakening is expected to be alloy specific, where a higher degree of both would increase SRC susceptibility. For example, Inconel $740 \mathrm{H}$ with $0.2 \%$ strain PWHT'ed at $800^{\circ} \mathrm{C}$ was susceptible to IG cracking due to strain localization at the grain boundaries resulting from $\gamma^{\prime}$ strengthening of the matrix and formation of soft precipitate-free zones due to $\gamma^{\prime}$ coarsening at grain boundaries (Fig. 14). With this in mind, it is important to note that the six parameters used to rank SRC susceptibility (ductility, percentage of stress relaxed, hardness, failure time, fracture mode, and secondary cracks) correlate directly or indirectly with both precipitate formation and grain boundary weakening. For example, the increase in hardness (with respect to the base metal) in the simulated HAZ is a direct measure of precipitation, while smaller percentage of stress relaxed during PWHT and lower time to fracture are indicative of the faster precipitation kinetics. Similarly, low- 


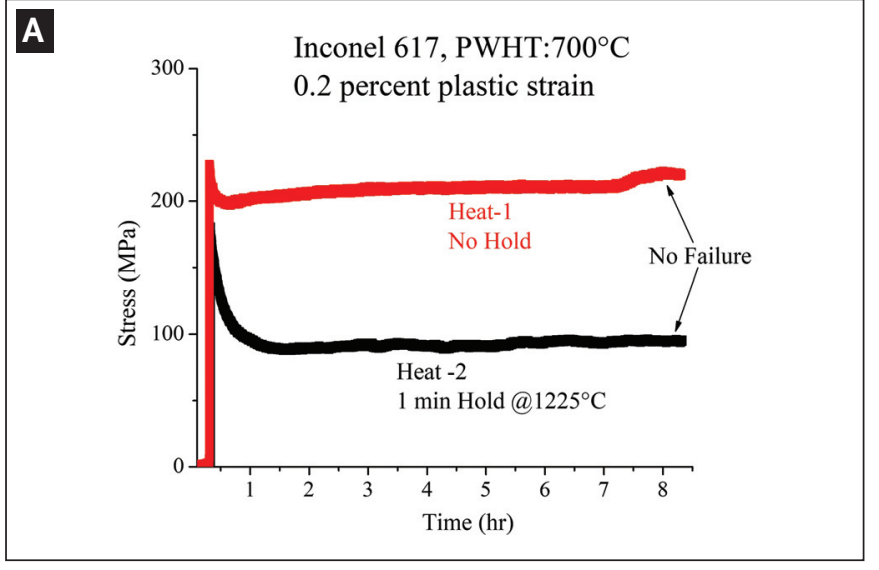

C

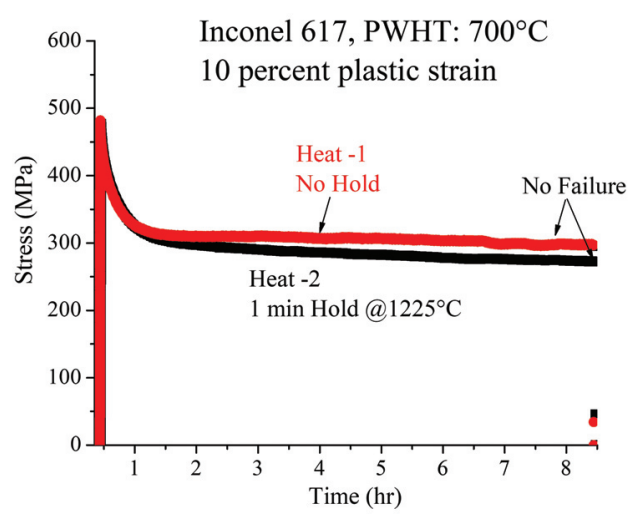

B

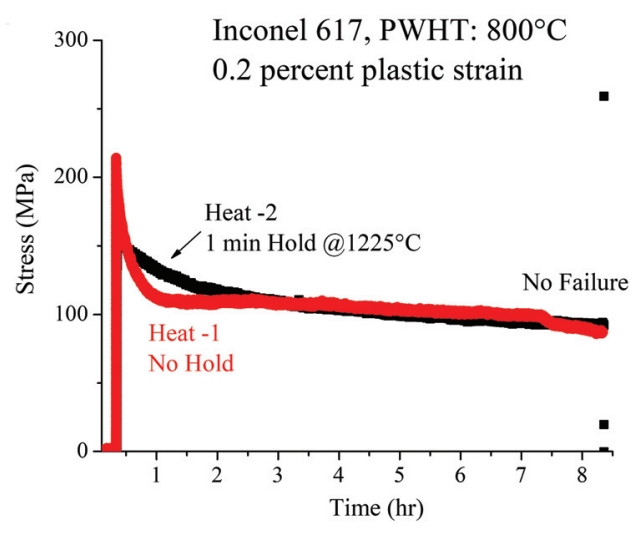

D

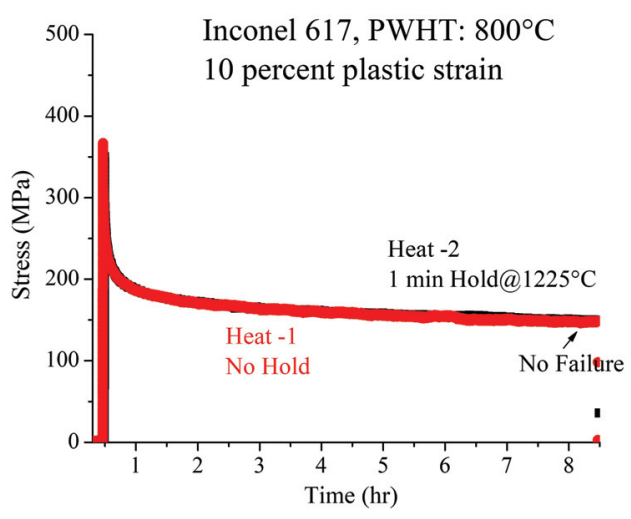

Fig. 22 - Stress vs. time plots comparing stress relaxation in Incone $l^{\circledR} 617$ samples with and without a 1-min hold at peak temperature at the following test conditions: $\mathrm{A}-700^{\circ} \mathrm{C}$ with $0.2 \%$ plastic strain; $\mathrm{B}-800^{\circ} \mathrm{C}$ with $0.2 \%$ plastic strain; $\mathrm{C}-700^{\circ} \mathrm{C}$ with $10 \%$ plastic strain; $D-800^{\circ} \mathrm{C}$ with $10 \%$ plastic strain.

er ductility, IG fracture mode, and IG secondary cracks represent the combined effect of both precipitation and grain boundary weakening. Therefore, the susceptibility number (that combined all the six parameters) is a way of capturing these factors that control SRC susceptibility.

\section{Conclusion}

The SRC susceptibility of a range of ferritic and austenitic alloys was tested at two strain levels under a range of PWHT temperatures using Gleeble-based techniques. Six measures of SRC susceptibility were acquired from the test results, and a robust ranking methodology for SRC susceptibility was developed. A sensitivity test was also performed for the ranking methodology followed by microstructural characterization to comprehend the mechanism of SRC failure in alloys. From the above work, the following conclusions can be drawn:

1) The Gleeble-based SRC test methodology developed in this work reproduced the low ductility IG fracture in a variety of alloys tested under different test conditions. Six parameters were identified as a measure of SRC susceptibility, namely ductility, percentage stress relaxed, hardness increase at fracture, failure time, fracture mode, and secondary cracks below the fracture.

2) An SRC susceptibility ranking method was developed based on the risk priority number used in failure modes and effect analysis. A sensitivity analysis demonstrated that the ranking methodology is robust and does not change significantly with reasonable variations to the severity and detectability values.

3) The ferritic alloys were most susceptible to SRC at PWHT of $600^{\circ} \mathrm{C}$. Cracking susceptibility of the austenitic alloys was highest at $800^{\circ}$ and $700^{\circ} \mathrm{C}$ followed by $900^{\circ} \mathrm{C}$. The least SRC susceptibility was observed at $1000^{\circ} \mathrm{C}$ irrespective of the alloy.

4) The following alloys and test conditions were shown to be susceptible to SRC: Grade $22 \mathrm{~V}(0.2 \%$ plastic strain at PWHT of $500^{\circ}, 600^{\circ}$, and $\left.700^{\circ} \mathrm{C}\right)$, Grade $22(0.2 \%$ plastic strain at PWHT of $\left.600^{\circ} \mathrm{C}\right)$, Haynes $282(10 \%$ plastic strain at PWHT of $\left.700^{\circ}, 800^{\circ} \mathrm{C}\right), 347 \mathrm{H}(10 \%$ plastic strain at PWHT of $\left.700^{\circ}, 800^{\circ} \mathrm{C}\right)$, and $740 \mathrm{H}(0.2$ and $10 \%$ plastic strain at PWHT of $800^{\circ} \mathrm{C}$ ).

5) The following alloys and test conditions were shown to be moderately susceptible to SRC: Haynes 230 (10\% plastic strain at PWHT of $700^{\circ}$ and $\left.800^{\circ} \mathrm{C}\right)$, Haynes $282(0.2$ and $10 \%$ plastic strain at PWHT of $\left.900^{\circ} \mathrm{C}\right), 740 \mathrm{H}(0.2$ and $10 \%$ plastic strain at PWHT of $\left.900^{\circ} \mathrm{C}\right)$, and Grade $22(0.2 \%$ plastic strain at $\mathrm{PWHT}$ of $700^{\circ} \mathrm{C}$ ).

6) For Alloys 347H, Haynes 282, and Haynes 230, application of $10 \%$ plastic strain enhanced the SRC susceptibility. Inconel 617 was resistant to SRC even with the application of $10 \%$ plastic strain for a range of CGHAZ grain sizes.

7) Stress relief cracking in Alloys $740 \mathrm{H}$, Haynes 282, and Haynes 230 was associated with discontinuous coarsening or grain boundary precipitates. 


\section{Acknowledgments}

The authors would like to acknowledge the financial support from the National Science Foundation through the industry/university cooperative research center grant to the Manufacturing and Materials Joining Innovation Center (Ma2JIC). They would also like to thank Jack Debarbadillo and Brian Backer at Special Metals, Tapasvi Lolla and Michael Gagliano at Electric Power Research Institute, Jorge Penso at Shell, and Diego Garcia at Petrobras for their technical discussion and assistance.

\section{References}

1. International Energy Agency. 2016. Key world energy statistics. From http://www.iea.org/publications/freepublications/publication/ KeyWorld2016.pdf.

2. Shingledecker, J. 2015. Update on US DOE/ OCDO Ultra supercritical (A-USC) Steam Boiler and Turbine Consortium. DOE-FE Cross-Cutting Review Meeting.

3. Baker, B. A., Poole, J. M., Shoemaker, L. E., and Smith, G. D. 2007. Fabricating nickel alloys to avoid stress relaxation cracking. NACE Corrosion Conference and Expo, Houston, Tex.

4. Siefert, J. A., and Tanzosh, J. M. Stress relaxation cracking literature review. Babcock and Wilcox Research Center.

5. Van Wortel, H. 2007. Control of relaxation cracking in austenitic high temperature components. NACE Corrosion Conference and Expo, Houston, Tex.

6. Bechetti, D. H. 2013. Microstructural evolution and creep rupture behavior of INCONEL ${ }^{\circledR}$ Alloy $740 \mathrm{H}{ }^{\circledR}$ fusion welds. M.S thesis. Bethlehem, Pa., Lehigh University. N.Y.

7. Sindo, K. 2003. Welding Metallurgy. Wiley \& Sons, New York,

8. Evans, N. D., Maziasz, P. J., Swindeman, R. W., and Smith, G. D. 2004. Microstructure and phase stability in INCONEL alloy 740 during creep. Scr Mater. 51(6): 503-507.

9. Tung, D. C., and Lippold, J. C. 2016. Self-restrained testing for residual stress driven cracking in nickel-based alloys. Materials Science and Engineering A 673: 158-166.

10. Pataky, G. J., Sehitoglu, H., and Maier, H. J. 2013. Creep deformation and mechanisms in Haynes 230 at $800^{\circ} \mathrm{C}$ and $900^{\circ} \mathrm{C}$. Journal of Nuclear Materials 443: 484-490.

11. Krishna, R., Atkinson, H. V., Hainsworth, S. V., and Gill, S. P. 2015. Gamma prime precipitation, dislocation densities, and TiN in creep-exposed Inconel 617 Alloy. Metall. Mater. Trans. A Phys. Metall. Mate. Sci. 47(1): 178-193.

12. Gladman, T. 1999. Precipitation hardening in metals. Mater. Sci. Technol. 15(1): 30-36.

13. Cai, D., Nie, P., Shan, J., Liu, W., Gao, Y., and Yao, M. 2006. Precipitation and residual stress relaxation kinetics in shot-peened Inconel 718. Journal of Materials Engineering and Performance 15(5): 614-617.

14. Berry, T., and Hughes, W. 1967. A study of the strain-age cracking characteristics in welded Rene 41 - Phase I (Strain age cracking characteristics in welded Rene 41 nickel base alloy). Welding Journal 46(8): 361-s to 370-s.

15. Franklin, J. E., and Savage, W. F. 1974. Stress relaxation and strain-age cracking in Rene 41 weldments. Welding Journal 53(9): 380-s to 387-s.

16. Shin, J., and McMahon, C. J. 1984. Mechanisms of stress relief cracking in a ferritic steel. Acta Metall. 32(9): 1535-1552

17. Kuhn, B., Ullrich, C., Tschaffon, H., Beck, T., and Singheiser, L. 2013. Stress-relaxation cracking test for welded joints. J Test Eval. 41(2): 1-10.

18. Hippsley, C. A., Briant, C. L., and Edwards, B. C. 1986.
Stress-relief cracking of $9 \mathrm{wt} \% \mathrm{Cr}$ steels containing $0.2 \mathrm{wt} \% \mathrm{Mo}$ Materials Science and Technology 2: 386-393.

19. David, S. A., and Woodhouse, J. J. 1987. Weldability test for thin sheet materials. Welding Journal 87(5): 129-s to 134-s.

20. ASTM E112: Standard Test Methods for Determining Average Grain Size. 2014. ASTM International, 13. DOI: 10.1520/E0112-13

21. Klueh, R. L., and Swindeman, R. W. 1983. Mechanical properties of a modified 2.25 Cr-1 Mo Steel for Pressure Vessel Applications. ORNL, Tennessee.

22. Zhang, S., Melfi, T., and Narayanan, B. K. 2016. Effects of precipitates on mechanical properties of P91 submerged arc welds. Science and Technology of Welding and Joining 21(2): 147-156. DOI: 10.1179/1362171815Y.0000000076

23. Shalchi Amirkhiz, B., and Xu, S. 2014. NbC Precipitation and deformation of SS $347 \mathrm{H}$ Crept at $850^{\circ} \mathrm{C}$. Microscopy and Microanalysis 20(3): 1494-1495. DOI: 10.101 7/S1431927614009209.

24. Sellappan, N., Nagarajan, D., and Palanikumar, K. 2015. Evaluation of risk priority number (RPN) in design failure modes and effects analysis (DFMEA) using factor analysis. Int. J. Appl. Eng. Res. 10.

25. Standard for Performing a Failure Modes and Effects Analysis and Establishing a Critical Items List. Flight Assurance Procedure 322 - 209. RSDO, NASA.

26. Hippsley, C. A., Knott, J. F., and Edwards, B. C. 1979. A study of SRC in $2.25 \mathrm{Cr} 1 \mathrm{Mo}$ steel - The effects of $\mathrm{P}$ segregation. Acta Metall. 28: 869-885.

27. Hippsley, C. A. 1983. Prediction of stress relaxation and stress relief cracking in SEN testpieces. Metal Science 17: 277-288.

28. You, C. P., Hippsley, C. A., and Knott, J. F. 1984. Stress relief cracking phenomena in high strength structural steel. Metal Science 18: 387-394.

29. Chang, J. C., Kim, B. S., and Heo, N. H. 2011. Stress relief cracking on the weld of T/P 23 steel. Procedia Engineering. DOI: 10.1016/j.proeng.2011.04.122

30. DuPont, J. N., Nawrocki, J. G., and Marder, A. R. 1998. The weldability of a modified 2.25 Cr-Mo steel. Proceedings of the Materials Conference on Joining of Advanced and Speciality Materials, 127132. Rosemont, Ill.

31. Nawrocki, J. G. Stress-relief cracking of a ferritic alloy steel. Weld World 45: 16-23.

32. Nawrocki, J. G., DuPont, J. N., Robino, C. V., and Marder, A. R. 2000. The stress-relief cracking susceptibility of a new ferritic steel - Part 1: Single-pass HAZ simulations. Welding Journal 79(12): 355-s to 362-s.

33. Bechetti, D. H., DuPont, J. N., De Barbadillo, J. J., Baker, B. A., and Watanabe, M. Microstructural Evolution of INCONEL ${ }^{\circledR}$ Alloy $740 \mathrm{H}^{\circledR}$ fusion welds during creep. Metallurgical and Material Transactions A. DOI: 10.1007/s11661-014-2682-6

34. Yan, C., Zhengdong, L., Godfrey, A., Wei, L., and Yuqing, W. 2014. Microstructure volution and mechanical properties of Inconel $740 \mathrm{H}$ during aging at 750C. Mater. Sci. Eng. A. 589: 153-164. DOI: 10.1016/j.msea.2013.09.076

35. Li, H., Ye, F., Zhao, J., et al. 2018. Grain boundary migration-induced directional coarsening of the $\gamma$ phase in advanced ultra-supercritical superalloy. Mater. Sci. Eng. A. 714: 172-178. DOI: 10.1016/J.MSEA.2017.12.089

36. Zhao, S. Q., Jiang, Y., Dong, J. X., and Xie, X. S. 2006. Experimental investigation and thermodynamic calculation on phase precipitation of INCONEL 740. Acta Metall. Sin. 19(6): 425-431. DOI: 10.1016/S1006-7191(06)62083-8

37. Nystrom, J. D., Pollock, T. M., Murphy, W. H., and Garg, A. 1997. Discontinuous cellular precipitation in a high-refractory nickel-base superalloy. Metallurgical and Materials Transaction A 28: 2443-2452.

38. Balluffi, R. W., and Cahn, J. W. 1981. Mechanism for diffusion induced grain boundary migration. Acta Metall. 29(3): 493-500. DOI: 10.1016/0001-6160(81)90073-0 
39. Livingston, J. D., and Cahn, J. W. 1974. Discontinuous coarsening of aligned eutectoids. Acta Metallurgica 22: 495-503.

40. Porter, D. A., and Easterling, K. E. 1992. Phase Transformations in Metals and Alloys. DOI: 10.1007/978-1-4899-3051-4

41. Duly, D., Simon, J. P., and Brechet, Y. 1995. On the competition between continuous and discontinuous precipitation in binary Mg-Al alloys. Acta Met. 43(1): 101-106.

42. Wadsworth, J., Ruano, O. A., and Sherby, O. D. Denuded zones, diffusional creep, and grain boundary sliding. Metallurgical and Materials Transaction A 33A: 219-229.

43. Wu, X.-J., and Koul, A. K. 1995. Grain boundary sliding in the presence of grain boundary precipitates during transient creep. Metallurgical and Materials Transaction A 26A: 905-914.

44. Tawancy, H. M. 1992. High temperature creep behaviour of an Ni-Cr-W-B alloy. J. Mater. Sci. 27: 6481-6489.

45. Yoon, J. G., Jeong, H. W., Yoo, Y. S., and Hong, H. U. 2015. Influence of initial microstructure on creep deformation behaviors and fracture characteristics of Haynes 230 superalloy at $900^{\circ} \mathrm{C}$. Mater. Charact. 101: 49-57. DOI: 10.1016/j.matchar.2015.01.002

46. Shin, J., and McMahon, C. J. 1984. Comparison of stress relief cracking in A 5082 and A 533 B pressure vessel steels. Metal Science (18): 403-410.

47. Yang, Y., Thomson, R. C., Leese, R. M., and Roberts, S. 2014 Microstructural evolution in cast Haynes 282 for applications in advanced power plants. Advances in Materials Technology for Fossil Power Plants: Proc. from $7^{\text {th }}$ International Conf. (EPRI 2013), Oct. 2013, Waikoloa, Hawaii. ASM International, pp. 143-154.

48. Osoba, L. O., Khan, A. K., and Adeosun, S. O. 2013. Cracking susceptibility after post-weld heat treatment in Haynes 282 nickel based superalloy. Acta Met. Sin. 26(6): 747-753. DOI:

10.1007/s40195-013-0252-3

49. Garrett, R. N., and Tien, J. K. 1982. Effects of cobalt on structure, microchemistry and properties of a wrought nickel-base superalloy. Metallurgical and Materials Transaction A 13A: 10211032.

50. White, H., Santella, M., and Specht, E. D. 2009. Weldability of HAYNES 282 alloy for new fabrications and after service exposure. Energy Materials 4(2): 84-91.

51. Bai, G., Li, J., Hu, R., Zhang, T., Kou, H., and Fu, H. 2011. Effect of thermal exposure on the stability of carbides in $\mathrm{Ni}-\mathrm{Cr}-\mathrm{W}$ based superalloy. Mater Sci Eng A 528(6): 2339-2344. DOI: 10.1016/j.msea.2010.11.088
52. Chen, X., Yang, Z., Sokolov, M. A., Erdman Iii, D. L., Mo, K., and Stubbins, J. F. 2012. Low cycle fatigue and creep-fatigue behavior of Ni-based alloy 230 at 850 1C. Mater. Sci. Eng. A 563: 152-162. DOI: 10.1016/j.msea.2012. 11.063

53. Han, Y., Xue, X., Zhang, T., Hu, R., and Li, J. 2016. Grain boundary character correlated carbide precipitation and mechanical properties of Ni-20Cr-18W-1Mo superalloy. DOI:

10.1016/j.msea.2016.05.028

54. Hu, R., Bai, G., Li, J., Zhang, J., Zhang, T., and Fu, H. 2012 Precipitation behavior of grain boundary $\mathrm{M}_{23} \mathrm{C}_{6}$ and its effect on tensile properties of $\mathrm{Ni}-\mathrm{Cr}-\mathrm{W}$ based superalloy. Mater. Sci. Eng. A. 548: 83-88. DOI: 10.1016/j.msea.2012.03.092

55. Shalchi Amirkhiz, B., Xu, S., Liang, J., and Bibby, C. 2016. Creep properties and TEM characterization of $347 \mathrm{H}$ stainless steel. Proceedings of the $36^{\text {th }}$ Annual Conference of the Canadian Nuclear Society, Toronto, Ontario, Canada.

56. Källqvist, J., Andrén, H.-O., Ka, J., Llqvist, È., and Andre, H.-O. 2000. Development of precipitate size and volume fraction of niobium carbonitrides in stabilised stainless steel. Materials Science and Technology (16): 1181-1185.

57. Shalchi Amirkhiz, B., and Xu, S. 2001. NbC precipitation and deformation of SS $347 \mathrm{H}$ crept at $850^{\circ} \mathrm{C}$. DOI:

10.1017/S1431927614009209

58. Zhou, Y., Liu, Y., Zhou, X., Liu, C., Yu, L., Li, C., and Ning, B. 2015. Processing maps and microstructural evolution of the type $347 \mathrm{H}$ austenitic heat-resistant stainless steel. Journal of Materials Research (30): 2090-2100.

59. Zhou, Y., Liu, C., Liu, Y., Guo, Q., and Li, H. 2016. Coarsening behavior of MX carbonitrides in type 347H heat-resistant austenitic steel during thermal aging. Int. J. Miner. Metall. Mater. 23(3): 283-293. DOI: 10.1007/s12613-016-1237-9

60. Di Martino, S. F., Faulkner, R. G., Hogg, S. C., Vujic, S., and Tassa, O. 2014. Characterisation of microstructure and creep properties of alloy 617 for high-temperature applications. Mater. Sci. Eng. A 619: 77-86. DOI: 10.1016/ j.msea.2014.09.046

61. Cabibbo, M., Gariboldi, E., Spigarelli, S., and Ripamonti, D. 2008. Creep behavior of INCOLOY alloy 617. J. Mater. Sci. 43(8): 2912-2921. DOI: 10.1007/s10853-007-1803-7

RISHI KANT (rik415@lehigh.edu) and JOHN DUPONT are with Lehigh University, Bethlehem, Pa..

\section{Authors: Submit Research Papers Online}

Peer review of research papers is now managed through an online system using Editorial Manager software. Papers can be submitted into the system directly from the Welding Journal page on the AWS website (aws.org) by clicking on "submit papers." You can also access the new site directly at editorialmanager.com/wj/. Follow the instructions to register or log in. This online system streamlines the review process, and makes it easier to submit papers and track their progress. By publishing in the Welding Journal, more than 70,000 members will receive the results of your research.

Additionally, your full paper is posted on the American Welding Society website for FREE access around the globe. There are no page charges, and articles are published in full color. By far, the most people, at the least cost, will recognize your research when you publish in the world-respected Welding Journal. 